University of Massachusetts Amherst ScholarWorks@UMass Amherst

Masters Theses 1911 - February 2014

2008

\title{
Patient Interpersonal Factors and the Therapeutic Alliance in Two Treatments for Bulimia Nervosa
}

Lotte Smith-hansen

University of Massachusetts Amherst

Follow this and additional works at: https://scholarworks.umass.edu/theses

Smith-hansen, Lotte, "Patient Interpersonal Factors and the Therapeutic Alliance in Two Treatments for Bulimia Nervosa" (2008). Masters Theses 1911 - February 2014. 189.

Retrieved from https://scholarworks.umass.edu/theses/189

This thesis is brought to you for free and open access by ScholarWorks@UMass Amherst. It has been accepted for inclusion in Masters Theses 1911 -

February 2014 by an authorized administrator of ScholarWorks@UMass Amherst. For more information, please contact

scholarworks@library.umass.edu. 


\title{
PATIENT INTERPERSONAL FACTORS AND THE THERAPEUTIC ALLIANCE IN TWO TREATMENTS FOR BULIMIA NERVOSA
}

\author{
A Thesis Presented \\ by \\ LOTTE SMITH-HANSEN
}

Submitted to the Graduate School of the

University of Massachusetts Amherst in partial fullments

of the requirements for the degree of

MASTER OF SCIENCE

September 2008

Clinical Psychology 


\section{PATIENT INTERPERSONAL FACTORS AND THE THERAPEUTIC ALLIANCE IN TWO TREATMENTS FOR BULIMIA NERVOSA}

A Thesis Presented

by

\section{LOTTE SMITH-HANSEN}

Approved as to style and content by:

Michael J. Constantino, Chair

Aline Sayer, Member

Elizabeth Harvey, Member

Ronnie Janoff-Bulman, Member

Melinda Novak, Department Head

Department of Psychology 


\section{ACKNOWLEDGMENTS}

First of all, I want to thank the members of my thesis committee. I am indebted to Mike Constantino for his thorough reviews of many long drafts and for his overall guidance of this project. I appreciate the statistical consultations with Aline Sayer, as well as the helpful comments from Lisa Harvey and Ronnie Janoff-Bulman. In addition, I am thankful for the statistical guidance provided by JuliAnna Smith and for the data set provided by Stewart Agras and his colleagues. 


\author{
ABSTRACT \\ PATIENT INTERPERSONAL FACTORS AND THE THERAPEUTIC ALLIANCE IN \\ TWO TREATMENTS FOR BULIMIA NERVOSA \\ SEPTEMBER 2008 \\ LOTTE SMITH-HANSEN, B.A., UNIVERSITY OF TEXAS AT AUSTIN \\ M.A., TEXAS STATE UNIVERSITY \\ Directed by: Professor Michael J. Constantino
}

Although the therapeutic alliance is a robust predictor of psychotherapy outcomes, less is known about specific factors that influence its development. The present study examined the association between patient-rated alliance and several patient interpersonal factors (distress, rigidity, \& style) in the context of a randomized clinical trial comparing cognitive-behavioral therapy (CBT) and interpersonal therapy (IPT) for bulimia nervosa. Using hierarchical linear modeling, the study found that early and middle alliance quality were both negatively associated with patients' baseline interpersonal distress and positively associated with baseline interpersonal affiliation. Middle alliance quality was also predicted by interactions between treatment group and rigidity, treatment group and affiliation, and treatment group and control. Overall, the rate of alliance growth was higher in IPT than in CBT. Using group-based trajectory analysis, the study found three divergent patterns of alliance development in the sample (high \& improving, low \& improving, and low \& stable) and detected group mean differences between two of the trajectory groups in terms of patient interpersonal distress and hostile-submissiveness. 


\section{TABLE OF CONTENTS}

Page

ACKNOWLEDGMENTS .....................................................ii

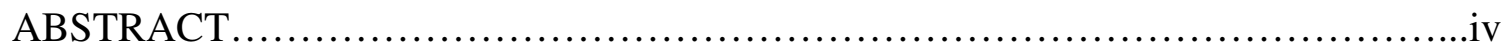

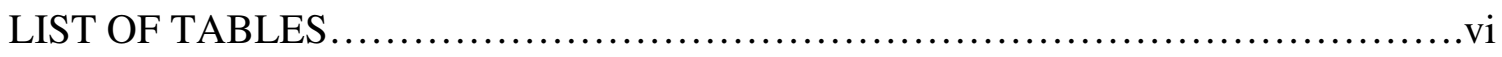

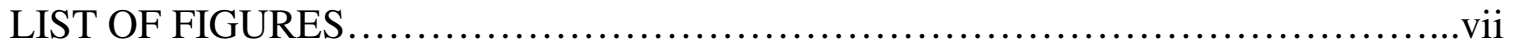
CHAPTER

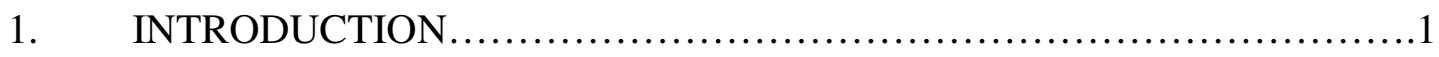

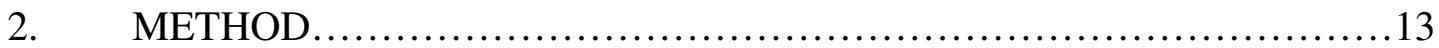

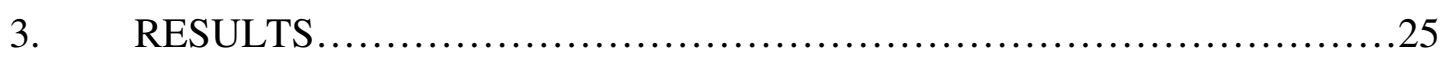

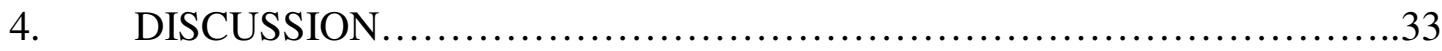

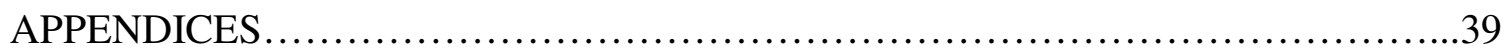

A. INVENTORY OF INTERPERSONAL PROBLEMS - CIRCUMPLEX SCALES...40

B. HELPING ALLIANCE QUESTIONNAIRE ..................................42

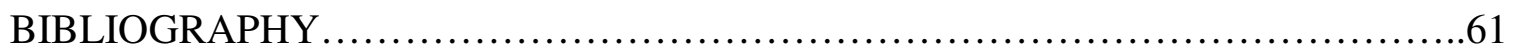




\section{LIST OF TABLES}

Page

1. Cross-Reference Table for Labels and Descriptions of the Subscales of the Inventory of Interpersonal Problems - Circumplex Scales (IIP-C) $\ldots \ldots \ldots \ldots \ldots \ldots \ldots \ldots \ldots \ldots \ldots . \ldots 4$

2. Descriptive Statistics for Alliance and Interpersonal Variables......................45

3. Predicting Early Alliance (Week 2) with Interpersonal Variables: Standardized Coefficients.

4. Predicting Middle Alliance (Week 10) with Interpersonal Variables: Standardized Coefficients.

5. Predicting Rate of Change in Alliance with Interpersonal Variables: Standardized Coefficients

6. Final Trimmed Models for Predicting Early and Middle Alliance, and Rate of Change in Alliance, with Interpersonal Variables: Standardized Coefficients. ... .51

7. Descriptive Statistics and Group Differences for Interpersonal Variables in Three Alliance Trajectory Groups. 


\section{LIST OF FIGURES}

Page

1. Circumplex model of interpersonal problems. Adapted from Ruiz et al. (2004).........53

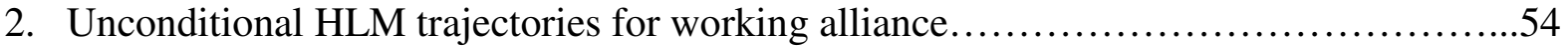

3. Relation between alliance and interpersonal rigidity displayed for two treatment

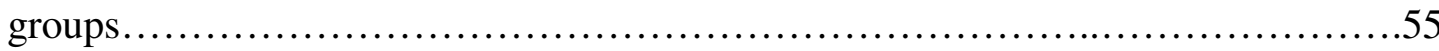

4. Relation between alliance and interpersonal control displayed for two treatment groups................................................................ 56

5. Relation between alliance and interpersonal affiliation displayed for two treatment

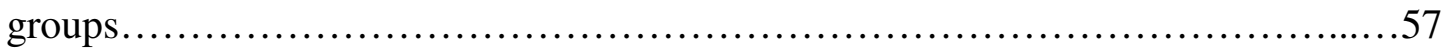

6. Rates of growth in the alliance in two treatment groups...........................58

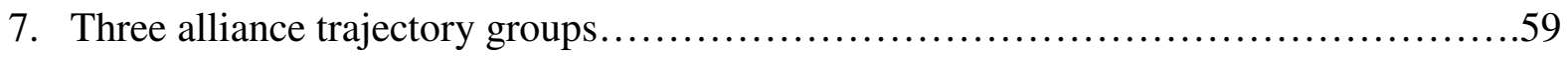

8. Multivariate outlier from Level 2 residuals in the HLM analysis predicting middle alliance 


\section{CHAPTER 1}

\section{INTRODUCTION}

The patient-therapist relationship has been firmly established as an important therapeutic change principle (Castonguay \& Beutler, 2006; Norcross, 2002). The therapeutic alliance has been conceptualized as a particularly important component of the patient-therapist relationship (Horvath \& Bedi, 2002). Although varying (and often theory-specific) definitions of the alliance have been advanced, virtually all reflect to some degree the patient and therapist's collaborative engagement in the treatment process in the context of a positive affective bond (Constantino, Castonguay, \& Schut, 2002; Gaston, 1990; Luborsky, 1976). Underscoring such similarities, Bordin (1979, 1994) articulated an influential transtheoretical model of the alliance that specifically emphasizes the patient and therapist's agreement on the tasks and goals of therapy and their formation of a personal bond.

After decades of substantial empirical attention, the alliance has been consistently and robustly associated with patient engagement and improvement across a variety of clinical problems, forms of treatment, and theoretical perspectives (see Castonguay, Constantino, \& Holtforth, 2006). Three systematic meta-analyses of this association have demonstrated overall Cohen's (1988) $d$ effect sizes between .21 and .26 (Horvath \& Bedi, 2002; Horvath \& Symonds, 1991; Martin, Garske, \& Davis, 2000), showing a stronger relation with outcome than specific techniques (see Wampold, 2001). With the clinical importance of the patient-therapist relationship well-documented, a second wave of alliance research has focused on examining the factors that may foster or impede its development (Castonguay et al., 2006; Safran, Muran, Samstag, \& Stevens, 2001). 


\section{Correlates of the Therapeutic Alliance}

Both patient and therapist characteristics have been shown to be associated with the therapeutic alliance. For example, therapist warmth, flexibility, and interpretive accuracy have been positively associated with alliance quality (see Ackerman \& Hilsenroth, 2003), while therapist rigidity, criticalness, and inappropriate self-disclosures have been negatively associated with alliance quality (see Ackerman \& Hilsenroth, 2001). Furthermore, the nature of the alliance has been differentially associated with the therapist's own interpersonal history, interpersonal style, and self-concept (e.g., Henry, Strupp, Butler, Schacht, \& Binder, 1993; Hersoug, 2004; Hersoug, Hoglend, Monsen, \& Havik, 2001; Hilliard, Henry, \& Strupp, 2000).

For patients, characteristics such as psychological-mindedness, expectation for change, ego strength, and high self-affiliation have been positively associated with alliance quality, while avoidance, defensiveness, hopelessness, negative introject, and perfectionistic attitudes have been negatively associated with alliance quality (see Constantino et al., 2002). In addition to these intrapsychic factors, patient interpersonal characteristics have been shown to relate to the alliance. Specifically, patient attachment style has been associated with the therapeutic alliance in several studies such that patients with secure attachment styles were more likely to have favorable therapeutic relationships, while those with fearful, preoccupied, anxious, or dismissive attachments had more difficulty establishing or maintaining a good alliance (e.g., Dolan, Arnkoff \& Glass, 1993; Eames \& Roth, 2000; Rubino, Barker, Roth, \& Fearson, 2000). Additionally, patients who possess poor object relations or have experienced negative early relationships with important others have been shown to have difficulty forming 
quality alliances with their therapists (e.g., Hilliard et al., 2000; Kokotovic \& Tracey, 1990; Piper, Azim, Joyce, \& McCallum, 1991; Piper, Boroto, Joyce, \& McCallum, 1995). Such associations make sense from an interpersonal perspective in that the interpersonal behaviors and patterns that a patient brings to therapy should invariably affect the (inherently interpersonal) therapeutic alliance (e.g., Kiesler \& Watkins, 1989; Safran \& Muran, 2000; Safran \& Segal, 1990).

\section{Circumplex Models of Interpersonal Functioning}

According to Muran, Segal, Samstag, and Crawford (1994), many studies examining the influence of patients' pre-existing interpersonal characteristics on the therapy relationship have subscribed to a "uniformity myth" by assuming that interpersonal problems are one-dimensional. This approach, however, is in stark contrast to theoretical and empirical literatures that speak to the multidimensional nature of interpersonal functioning and interpersonal problems (e.g., Horowitz, 2004; Pincus \& Ansell, 2003; Wiggins, 1982). Furthermore, studying interpersonal functioning in only a global sense may mask specific types of interpersonal characteristics or problems that have an impact on the alliance, and may also make it difficult to interpret equivocal findings (Muran et al., 1994).

To address the shortcomings of the "uniformity myth," some researchers have argued for the usefulness of circumplex models of interpersonal behavior (see Gurtman, 1992, 1996; Wiggins, 1982). In brief, circumplex models are derived from interpersonal theory (e.g., Carson, 1969; Kiesler, 1983, 1986, 1996; Leary; 1957) and consist of two orthogonal dimensions: control and affiliation. When these two axes are conceptualized as two intersecting lines, they form a circular arrangement in which various combinations 
of interpersonal behavior can be represented graphically on a plane with the vertical axis representing control (ranging from dominance to submission) and the horizontal axis representing affiliation (ranging from closeness to distance).

One application of the circumplex model is to represent interpersonal problems according to the Inventory of Interpersonal Problems - Circumplex Scales (IIP-C; Alden et al. 1990; Horowitz, Alden, Wiggins, \& Pincus, 2000). The IIP-C is a 64-item circumplex version derived from the original 127-item IIP (Horowitz et al., 1988). The IIP-C comprises eight subscales, or octants, derived from different degrees of control and affiliation that manifest as problematic interpersonal styles. As depicted in Figure 1, the eight subscales are Domineering, Intrusive, Self-Sacrificing, Overly Accommodating, Nonassertive, Socially Inhibited, Cold, and Vindictive. ${ }^{1}$ These eight scales make up four quadrants of interpersonal behavior, which are Friendly-Dominant, Friendly-submissive, Hostile-Submissive, and Hostile-Dominant. For example, dominant behavior reflects excessive control and neutral affiliation, self-sacrificing behavior reflects excessive affiliation and neutral control, and vindictive behavior reflects a combination of excessive control and inhibited affiliation.

In addition to capturing these specific interpersonal styles, or dimensions, the IIPC assesses structural characteristics of problematic interpersonal functioning - i.e., overall level of interpersonal distress (elevation) and specificity or rigidity of interpersonal problems (amplitude; Gurtman \& Balakrishnan, 1998; Gurtman \& Pincus, 2003). The measure of interpersonal distress reflects the degree to which an individual's presenting issues are specific to problems pertaining to his or her interpersonal functioning, while interpersonal rigidity, or specificity, reflects the degree to which an 
individual's social problems are clustered around certain types of behaviors or are more diffuse (in other words, the degree to which the circumplex profile has well-defined peaks). Thus, the IIP-C is an example of how a circumplex instrument can capture interpersonal behavior at multiple levels, which in this case allows for a more differential and specific examination of the influence of interpersonal problems on the therapeutic alliance (Muran et al., 1994; Ruiz et al., 2004).

Interpersonal Problems as Predictors of the Alliance

Using the IIP or IIP-C, several studies have examined adult patients' interpersonal problems as predictors of the alliance in different types of treatment. The findings across these studies have differentially implicated problems with affiliation and problems with control in the prediction of the alliance. For example, Muran et al. (1994) found that problems of a friendly and submissive nature were positively associated with components of the therapeutic alliance in cognitive therapy (CT) for depression and anxiety. More specifically, patients whose interpersonal problems were marked by social-avoidance, non-assertiveness, exploitability, and over-nurturance reported greater agreement with their therapists on the therapy tasks. Exploitability and over-nurturance were also positively associated with agreement on therapy goals and overall alliance. However, because no particular types of interpersonal problems were associated with the bond component, the authors reasoned that the task and goal components in this study may have been more reflective of "compliance" than alliance.

In a study of brief psychodynamic (PD) therapy for mostly mood and anxiety disorders, Beretta et al. (2005) also found that alliance quality (as assessed by the patient after the third session) was positively related to interpersonal problems of an overly 
affiliative nature. Overall interpersonal distress, however, was associated with lower alliance quality. In a study of PD treatment of patients with a variety of clinical problems, Saunders (2001) found that interpersonal problems of a detached nature were negatively associated with specific aspects of the patient-rated alliance, including the affective bond, the patient's role investment in the therapy, as well as his or her sense of mutual affiliation with the therapist and ratings of therapist empathy.

Connolly Gibbons et al. (2003) examined the prediction of early and midtreatment patient-rated alliance quality from patients' baseline interpersonal problems in both CT and supportive-expressive therapy (SE) for heterogeneous conditions. Similar to Beretta et al. (2005), overall interpersonal distress was negatively associated with patient-rated alliance quality across both conditions. However, this association was present only for the midtreatment alliance rating, as opposed to Beretta et al.'s early treatment rating. Connolly Gibbons et al. also found that hostile-dominant types of problems (i.e., domineering, vindictive, cold, \& socially-avoidant) were negatively associated with alliance quality at both the early and middle phases of treatment in both CT and SE.

Nevo (2002) found that both the affiliation and the control dimensions of interpersonal problems were important correlates of the alliance in a treatment for adults who had experienced childhood sexual abuse. Similar to the other findings presented, problems on the friendly end of the affiliation dimension were associated with higher initial alliance ratings. In contrast to the other findings presented, problems on the dominance end of the control dimension were also positively associated with initial alliance ratings. Paivio and Bahr (1998), however, found that problems related to 
hostility, nonassertiveness, social avoidance, and coldness were negatively related to the alliance in experiential therapy addressing "unfinished business."

To summarize, several studies have examined how patient interpersonal factors (measured by the IIP or IIP-C) are related to the therapeutic alliance. However, most studies have examined only one or two aspects of interpersonal functioning (i.e., overall distress and/or types of interpersonal problems, or style). To my knowledge, no studies have concurrently examined all three aspects of interpersonal problems as operationalized by the IIP-C (distress, rigidity, \& style) in the prediction of the therapeutic alliance. Furthermore, the findings presented above reflect some inconsistency in which aspects of interpersonal problems are most relevant for fostering or impeding the development of the therapeutic alliance. Thus, it seems that more research is needed to clarify the associations between alliance and interpersonal problems. It also seems important to examine these relationships in the context of controlled treatment trials for more homogeneously defined populations to get a better understanding of how patient interpersonal factors may be differentially related to the alliance in different treatments and for different patients.

\section{Predictors of Alliance Development Over Time}

As noted earlier, the alliance is a consistent predictor of treatment outcome (Castonguay et al., 2006). In the majority of studies that have examined this association, the alliance has been measured at one or more specific points in time. More recently, however, researchers have also examined how different patterns of alliance development relate to outcome. For example, several studies have demonstrated that U-shaped alliance trajectory is associated with patient improvement (Horvath \& Marx 1991; Kivlighan \& 
Shaughnessy, 2000; Patton, Kivlighan, \& Multon, 1997). This pattern has been hypothesized to reflect the presence of a difficult, but productive working-through phase in the middle of treatment that manifests as lower alliance ratings. However, Stiles et al. (2004) found no U-shaped alliance patterns in their sample, but did detect a group of clients with brief dips in ratings suggestive of alliance ruptures with subsequent repair (V-shaped deflections), and these clients reported greater symptomatic improvement than patients with different alliance trajectories. Still other studies have found that a flat alliance (vs. a slope in the alliance over time) may be associated with better outcomes (Bachelor \& Salame, 2000; Krupnick, Sotsky, Simmens, \& Moyer, 1996). Given the inconsistent findings, it seems important to continue to examine patterns of alliance development in psychotherapy studies. What is clear is that differential patterns do seem to have a bearing on outcome. Thus, in line with the second wave of alliance research, it seems important to examine correlates of different alliance patterns within different treatment for different disorders. A small literature has begun to emerge in this area.

In the Beretta et al. (2005) study discussed above, the authors used cluster analysis and found three distinct types of alliance trajectories across time: (1) high and stable, (2) low and stable, and (3) linear progression (growth). The patients in these three groups demonstrated some significant differences on several interpersonal problem factors. Specifically, patients with low and stable alliances reported fewer problems related to excessive affiliation, as well as more problems related to coldness and socialinhibition relative to the other two alliance groups. Additionally, patients with progressively improving alliances reported significantly fewer problems related to excessive control than the other two groups. 
In their study of time-limited cognitive behavioral (CB) and psychodynamicinterpersonal (PI) treatments for depression, Stiles et al. (2004) also used cluster analysis and detected four different alliance patterns: (1) modestly positive slope and high variability, (2) almost no slope and very low variability, (3) negative slope, high variability, and slightly upward-turning curve, and (4) positive slope, low variability, and negatively accelerated (inverted-U-shaped) curve. However, only the third pattern was predicted by patient interpersonal problems. Specifically, the alliance patterns of these patients were characterized by high initial ratings, rapid deterioration, and great sessionto-session variability, and as a group these patients had more interpersonal problems of an overly-involved, or intrusive, nature than the other three groups.

In the Nevo (2002) study discussed above, the author used hierarchical linear modeling and found that patients with interpersonal problems related to excessive control had high initial alliance ratings with upward-sloping trajectories, while patients struggling with excessive affiliation had initially high alliance quality followed by downward-sloping trajectories. Connolly Gibbons et al. (2003) also used hierarchical linear modeling and found that the alliance changed significantly across treatment and showed significant variability across patients in terms of level and growth. However, no interpersonal problem variables were associated with growth in alliance over time.

In summary, although several studies have examined how different alliance patterns are related to therapy outcome, only four studies were found that explored how patient interpersonal problems relate to the development of the therapeutic alliance over time. Given the clinical usefulness of these types of findings, more research is needed to 
clarify how the patient's interpersonal vulnerabilities and sensitivities manifest in patterns of alliance development.

Specific Aims and Hypotheses of the Present Study

Data for the current study were derived from a large randomized clinical trial comparing cognitive-behavioral therapy (CBT) and interpersonal therapy (IPT) for bulimia nervosa (BN) (Agras, Walsh, Fairburn, \& Kraemer, 2000). It should be noted that a previous study using the same dataset demonstrated that the early alliance was positively associated with patient outcome in both CBT and IPT (Loeb et al., 2005). In addition, Constantino, Arnow, Blasey, and Agras (2005) examined predictors of alliance development in the same sample. The authors found that several patient characteristics differentially predicted alliance quality in CBT and IPT, including patients' baseline interpersonal problems. For patients receiving IPT (but not CBT), more interpersonal problems were associated with poorer alliance quality at midtreatment. While Constantino et al.'s (2005) study shed some light on patient correlates of the alliance in the treatment of $\mathrm{BN}$, their study provided only a global assessment of problems in interpersonal relating (i.e., interpersonal distress as assessed by the mean item rating of the original IIP; Horowitz, Rosenberg, Baer, Ureño, \& Villaseñor, 1988).

The present study extended the previous alliance work on this sample by examining all three specific aspects of patient interpersonal problems (interpersonal distress, rigidity, \& style) as predictors of the therapeutic alliance both within and across the two treatments, and both statically and dynamically.

First, I examined the prediction of the early alliance. Based on Constantino et al.'s (2005) findings, I did not expect the structural characteristics of interpersonal distress or 
rigidity to relate to the early alliance in either treatment. In both CBT and IPT for BN, the early focus is on psychoeducation. Thus, interpersonal problems may pose less of a problem for alliance development at this early stage. However, based on the previously reviewed literature (e.g., Connolly Gibbons et al., 2003; Muran et al., 1994), I predicted that problems of affiliation would be positively associated with early alliance, while control problems would be negatively associated with early alliance.

Second, I examined the prediction of the alliance at midtreatment. Based on the findings of Connolly Gibbons et al. (2003) and Constantino et al. (2005), I expected that level of interpersonal distress would be negatively related to the midtreatment alliance, reflecting the possibility that patient interpersonal problems may have had sufficient time to manifest in the therapy relationship. In addition, I hypothesized that interpersonal rigidity would be negatively related to the alliance at midtreatment, although to my knowledge no studies have examined rigidity and the alliance. Based on the literature, and similar to early alliance predictions, I predicted that problems of affiliation would be positively associated with middle alliance, while control problems would be negatively associated with middle alliance.

Third, I examined interpersonal factors as predictors of linear growth in the alliance. I hypothesized that there would be significant change in the therapeutic alliance over the course of treatment, and that there would be significant variability between patients in terms of both level and pattern of change in the alliance. However, no specific hypotheses were advanced given the limited research on this question and the mixed findings for the few studies that have examined this association. 
Fourth, I conducted exploratory analyses to examine differences between groups of patients with different alliance trajectories in terms of interpersonal distress, rigidity, and style.

\section{Strengths of the Study}

The present study attempted to add some clarity to previous equivocal findings regarding the link between specific patient interpersonal problems and the therapeutic alliance. It examined the multidimensional nature of interpersonal problems by assessing general interpersonal distress, interpersonal rigidity, and interpersonal style using an empirically and theoretically robust circumplex measure (the IIP-C). The study built on prior research by examining the alliance both within and across two standardized, wellcontrolled treatments, using a large and homogeneous sample of patients with a specific disorder (bulimia nervosa) for which the alliance construct has received limited empirical attention. Finally, it expanded upon previous studies by examining correlates of the alliance as measured at various points in time (early \& middle treatment) and as a trajectory over the course of treatment. 


\section{CHAPTER 2}

\section{METHOD}

The study used data from a multi-site randomized clinical trial at Stanford University and Columbia University that compared the effectiveness of CBT and IPT for BN (see Agras et al., 2000 for additional details regarding the main outcome study).

\section{Participants}

Patients. Two hundred and twenty women (110 at each site) meeting criteria for BN according to the Diagnostic and Statistical Manual of Mental Disorders (3rd ed., rev.; DSM-III-R; American Psychiatric Association, 1987) were randomly assigned to CBT or IPT. The patients averaged 28.1 years of age $(S D=7.2)$. The majority of the patients were Caucasian (77\%), while 11\% were Hispanic, $6 \%$ were African American, 5\% were Asian, and $1 \%$ was American Indian. The majority of the patients $(70.8 \%)$ were never married, while $14.6 \%$ were married, $9.1 \%$ divorced, $5 \%$ divorced and remarried, and $0.5 \%$ widowed.

The exclusion criteria included (a) having a severe physical or psychiatric disorder with potential to interfere with the treatment (e.g., psychosis), (b) having a current DSM-III-R diagnosis of anorexia nervosa, (c) being engaged in any psychosocial treatment, (d) being on psychotropic medications, (e) being pregnant, and (f) having had a prior adequate trial of CBT or IPT. Of the 220 patients in the sample, $22 \%$ also met criteria for major depressive disorder (MDD), while 37\% also met criteria for a personality disorder at the time of entry into the study. Lifetime rates were $53 \%$ for MDD and $23 \%$ for substance abuse. 
At the start of the trial, the two groups were equivalent on demographic variables and eating disorder symptoms, except that CBT patients showed significantly higher purge episodes and eating concerns compared to IPT patients. Several significant site differences were present. Patients at the Stanford site were older and more likely to have been diagnosed with substance abuse or dependence in their lifetime. Patients at the Columbia site had a longer purging duration, were less likely to have had a previous diagnosis of anorexia nervosa, had fewer concerns about eating and shape, and reported less global symptomatology. Of the 220 patients randomized, 154 (70\%) completed treatment, while $57(26 \%)$ dropped out of the study (31 in CBT \& 26 in IPT) and $9(4 \%)$ were withdrawn for clinical reasons.

Therapists. At each site, 4 therapists treated approximately equal numbers of patients in each of the two treatment conditions. All 8 therapists (7 doctoral-level psychologists \& 1 psychiatrist) were experienced in the treatment of eating disorders and received extensive training in $\mathrm{CBT}$ and IPT for $\mathrm{BN}$ prior to the trial. Therapists were supervised weekly to ensure standard and competent protocol administration. Prior analyses revealed comparable degrees of treatment adequacy between the two conditions (see Agras et al., 2000).

\section{Treatments}

CBT and IPT are both manual-driven treatments that have received prior empirical support of efficacy for BN (Agras, 1993). Both treatments involved 19 individual, outpatient psychotherapy sessions conducted over the course of 20 weeks. Sessions were 50 minutes long and were delivered twice-weekly for the first two weeks, weekly for the next 12 weeks, and biweekly for the remaining time. 
Cognitive-Behavioral Therapy. When conducting CBT, therapists adhered to a treatment protocol developed by Fairburn, Marcus, and Wilson (1993). This directive approach addresses the main symptomatic features of BN, including (a) binge eating, (b) purging and other compensatory behaviors, and (c) excessive and often distorted body shape and weight concerns. In the first phase of treatment, therapists present a cognitivebehavioral model of BN and attempt to educate patients about the nature of their condition, the processes that maintain it, and its negative physiological consequences. Patients also monitor their food intake and compensatory behaviors. The second phase of treatment involves a continued focus on strategies to reduce dietary restraint and irregular eating. In addition, treatment focuses on cognitive and behavioral strategies for testing and challenging distorted thoughts and assumptions, decreasing avoidance of feared foods, and implementing adaptive coping responses to binge-eating triggers. Finally, the third stage of treatment centers on maintaining treatment gains and preventing relapse.

Interpersonal Therapy. When conducting IPT, therapists adhered to a protocol originally developed for the treatment of depression by Klerman, Weismann, Rounsaville, \& Chevron (1984) and subsequently adapted for BN by Fairburn and colleagues (Fairburn, 1997; Fairburn, Jones, Peveler, Hope, \& O'Conner, 1993). IPT is an active, but non-directive treatment that focuses on the interpersonal difficulties in the patient's life. Although therapists initially draw a connection between the patient's interpersonal difficulties and symptoms of BN, this connection is only implied thereafter. Like CBT, IPT is composed of three phases. In Phase 1, an interpersonal model of therapy is presented and the patient is introduced to the four main realms of interpersonal difficulty: role disputes, role transitions, interpersonal deficits, and unresolved grief. The 
patient's eating disorder is placed within this interpersonal framework (e.g., a specific role dispute as a trigger for binge-eating). In Phase 2, the therapist maintains a nondirective stance in working with patients to implement adaptive interpersonal changes in their lives. Phase 3 focuses on feelings about termination, a review of treatment gains, and strategies for coping with future interpersonal distress. Specific attention to eating patterns, compensatory behaviors, or attitudes toward body shape and weight are proscribed in IPT. Moreover, this therapy involves neither self-monitoring nor specific behavioral instruction.

\section{Measures}

Inventory of Interpersonal Problems (IIP). The IIP was developed by Horowitz et al. (1988) and consists of 127 items that assess the extent of one's interpersonal difficulties (i.e., interpersonal inhibitions \& excesses). The measure consists of items such as "It is hard for me to trust other people" and "I fight with other people too much," and each item is rated on a 5-point Likert scale ranging from "not at all" to "very much." The 127 items reflect the two underlying dimensions of affiliation (closeness-distance) and control (dominance-submission) such that each item can be plotted on a twodimensional graph in terms of its degree of affiliation and dominance, respectively. For example, the item "It is hard for me to stay out of other people's business" reflects overly close and overly controlling behavior, while "It is hard for me to join in on groups" reflects distant and submissive behavior. Horowitz et al. (1988) examined the psychometric properties of the subscales of the IIP, and found good internal consistency (alphas ranging from .82 to .93 ), test-retest reliability ( $r$ s ranging from .81 to .98 ), and concurrent validity with the interpersonal scales of the Symptom Check List (SCL-90-R; 
Derogatis, 1977). Furthermore, the IIP has been found to be sensitive to clinical improvement over time in brief dynamic therapy (Horowitz et al., 1988), cognitive therapy (Vittengl, Clark, \& Jarrett, 2003), and pharmacological therapy (Markowitz et al., 1996).

Alden et al. (1990) applied the 127 IIP items to a circumplex model, creating a circular graph where the horizontal and vertical axes represent the affiliation and control dimensions, respectively. They divided this circular space into eight sections or subscales representing common types of interpersonal problems (or styles), including Domineering, Vindictive, Intrusive, Cold, Socially-Inhibited, Nonassertive, Overly-Accommodating, and Self-Sacrificing (as seen in Figure 1). In addition, of the original 127 items, Alden et al. (1990) selected the eight items with the strongest loading on each of the eight subscales, creating a 64-item circumplex measure (the IIP-C or IIP-64; see Appendix A).

Like the IIP, the IIP-C has been found by Horowitz et al. (2000) to have good psychometric properties, with internal consistency coefficients (alphas) ranging from .76 to .88 , test-retest coefficients ranging from .56 to .83 , and convergent validity correlations with the Beck Depression Inventory II (Beck, Steer, \& Brown, 1996) ranging from .33 to .48 , with the Beck Anxiety Inventory (Beck \& Steer, 1990) ranging from .31 to .44 , and with the Brief Symptom Inventory (Derogatis, 1993) ranging from .57 to .76 . Furthermore, Bartholomew and Horowitz (1991) found that interpersonal problems on the eight subscales related to attachment styles (secure, preoccupied, dismissing, \& fearful) in predictable ways.

For this study, variables were derived from the 64 items of the IIP-C, which were rated by patients on a Likert scale from 1 ("not at all") to 5 ("extremely"). ${ }^{2}$ All variables 
were derived in accordance with the formulas used by Ruiz et al. (2004). Each patient's level of interpersonal distress (elevation) was calculated by summing responses across the 64 items, and dividing this total by 8 . Thus, the theoretical range is 8 to 40 .

Several other variables were derived from formulas based on the eight subscale scores, i.e., each patient's total score on the Domineering, Vindictive, Intrusive, Cold, Socially-Inhibited, Nonassertive, Overly-Accommodating, and Self-Sacrificing scales. To calculate these subscale scores, responses were summed across the eight items on each of the eight subscales; thus, the theoretical range for each of the subscales is 8 to 40 .

Interpersonal affiliation and control were both calculated by formulas using the eight subscales weighted based on their proximity to the axes of affiliation and control, respectively (see Figure 1). Interpersonal affiliation was calculated by the following formula: Affiliation $=.25[$ Self-Sacrificing - Cold $+.71($ Intrusive - Vindictive Socially Inhibited + Overly Accommodating)]. Interpersonal control was calculated as follows: Control $=.25$ [Domineering - Nonassertive +.71 (Intrusive + Vindictive Socially Inhibited - Overly Accommodating)]. The theoretical range for both affiliation and control is -19.36 to 19.36 . Each patient's degree of interpersonal rigidity (amplitude) was calculated by summing the squared affiliation score and the squared control score, and taking the square root of this value. Thus, the theoretical range of this variable is 0 to 27.38.

Four quadrant scores were calculated, representing each patient's degree of (a) friendly-dominance, (b) friendly-submissiveness, (c) hostile-dominance, and (d) hostilesubmissiveness. The scores were calculated by the following formulas: Friendlydominance $=$ Intrusive $+(.707 \times$ Domineering $)+(.707 \times$ Self-Sacrificing $) ;$ Friendly- 
submissiveness $=$ Overly-Accommodating $+(.707 \mathrm{x}$ Self-Sacrificing $)+(.707 \mathrm{x}$

Nonassertive $) ;$ Hostile-dominance $=$ Vindictive $+(.707 \times$ Domineering $)+(.707 \times$ Cold $)$;

Hostile-submissiveness $=$ Socially Inhibited $+(.707 \times$ Nonassertive $)+(.707$ Cold $)$. The

theoretical range for each of the four quadrant scores is 19.31 to 96.56 .

Finally, as a measure of each patient's interpersonal style, the interaction of affiliation and control was calculated by multiplying the values of these two variables. This was done to capture each patient's "location" on the two-dimensional circumplex in a single variable. This was done because 1) the study had insufficient statistical power to use the eight subscale scores or the four quadrant scores as measures of interpersonal style in the same analytic model, and 2) using the eight subscale scores or four quadrant scores would cause problems with collinearity given the circumplex nature of the scales. Internal consistency (Cronbach's alpha) was good for the current sample. The overall reliability of all 64 items was .94 , and the reliability coefficients for the eight subscales ranged from .71 to .89 .

Helping Alliance Questionnaire (HAq). The HAq (Alexander \& Luborksy, 1986) is an 11-item self-report measure that assesses the quality of the therapeutic alliance from the patient's perspective. This instrument is based on Luborsky's (1976) conceptualization of the alliance, and reflects the patient's perception of receiving therapist-offered helpfulness and supportiveness, as well as his or her experience of working collaboratively with the therapist on agreed-upon treatment goals. Patients rate each item on a 6-point scale ranging from +3 ("I strongly feel it is true") to -3 ("I strongly feel it is not true"; see Appendix B). The HAq has been shown to possess good internal consistency and test-retest reliability, as well as good convergent validity with the 
California Psychotherapy Alliance Scale (CALPAS; Luborsky, Barber, Siqueland, \& Johnson, 1996). For this study, the total score for the HAq was used as the index of alliance quality. Thus, across the 11 items, the highest possible value was 33 while the lowest possible value was -33 . For this study, internal consistency reliability (Cronbach's alpha) was found to be good. The reliability across the 11 items was .84 at week 2 (following session 4) and .88 at week 10 (following session 12). ${ }^{3}$

Procedure

After being recruited by advertisements or referrals from local clinics, potential participants were initially screened by phone for study eligibility. Participants who were not ruled out at the initial screening were scheduled for an in-person, baseline clinical assessment with a trained research assistant. After obtaining informed consent, research assistants administered the Eating Disorder Examination (EDE; Cooper \& Fairburn, 1987; Fairburn \& Cooper, 1993) to assess for eating disorder symptomatology and the Structured Clinical Interview for the DSM-III-R (SCID; Spitzer, Williams, Gibbson, \& First, 1989) to assess for general psychopathology. If eligible for the study, participants also completed a baseline battery of self-report measures, including the full 127-item IIP and several other instruments not related to the current study. The HAq was administered following sessions 4, 12, and 19, during weeks 2, 10, and 20, respectively. At posttreatment, research assistants administered the EDE again.

\section{Analytic Strategy}

Given the longitudinal nature of the data, hierarchical linear modeling (HLM) was used to address the first three aims of the study. HLM captures the intercorrelation of the repeated responses and provides accurate estimates of the effects and standard errors. The 
HLM analyses used the sample of 207 patients who (a) completed the battery of selfreport measures during the pretreatment assessment, including the IIP, and (b) had at least one data point for the HAq.

To predict the early alliance, a model was used where the origin of time (i.e., where time is 0 ) was set at the $4^{\text {th }}$ session. Since the $4^{\text {th }}$ session occurred during week 2 , this was done by subtracting 2 from each original value of week, such that week 2 was rescaled as 0 , week 10 was rescaled as 8 , and week 20 was rescaled as 18 . This forced the intercept in the model to be interpreted as the predicted value of alliance at the end of week 2 (following the $4^{\text {th }}$ session). To predict the middle alliance, a second model was used where the origin of time (i.e., where time is 0 ) was set at the $12^{\text {th }}$ session. Since the $12^{\text {th }}$ session occurred during week 10 , this was done by subtracting 10 from each original value of week, such that week 2 was rescaled as -8 , week 10 was rescaled as 0 , and week 20 was rescaled as 10 . This forced the intercept in the model to be interpreted as the predicted value of alliance at the end of week 10 (following the $12^{\text {th }}$ session). The first model was used to predict growth in alliance over time, and the repeated measures were modeled as a linear function of time, scaled in weeks. With only three data points, the class of polynominal functions available is limited to a linear model. This defined the slope as the weekly change in alliance.

The HLM analysis used a two-level modeling strategy. In the first step, an unconditional model that included no predictors at Level 2 and only time as a predictor at Level 1 was fitted. This was done to assess whether the average level and average rate of change in alliance quality were significantly different from 0 , and if there was significant variation among the individual intercepts and slopes, respectively. In the second step, 
conditional models that included predictors of both the intercepts (early \& middle alliance) and the slope at Level 2 were fitted. The linear models were expressed as follows:

$$
\begin{aligned}
& y_{1 j}=\beta_{0 j}+\beta_{1 j}\left(T_{\text {week }}-2\right)_{i j}+r_{i j} \\
& \beta_{0 j}=\gamma_{00}+\gamma_{01}[\text { predictors }]+u_{0 j} \\
& \beta_{1 j}=\gamma_{10}+\gamma_{11}[\text { predictors }]+u_{1 j}
\end{aligned}
$$

Level 2 modeling proceeded in several steps. First, the two control variables of treatment site (Columbia vs. Stanford University) and treatment group (CBT vs. IPT) were examined both individually and together in terms of their associations with early alliance, middle alliance, and slope in alliance. Since the association between treatment site and early alliance was nearly significant, and treatment group was significantly associated with alliance slope, it was decided to retain both controls in all subsequent analyses. Next, the four main effect variables (distress, rigidity, control, \& affiliation) were examined individually and in all possible combinations of two, three, and four variables in order to determine whether they significantly predicted the two intercepts (early \& middle alliance) and alliance slope, and whether any combination of the four variables showed problems with collinearity. Subsequently, five interaction variables (control by affiliation, treatment by distress, treatment by rigidity, treatment by control, \& treatment by affiliation) were examined individually and as a block to determine whether they significantly predicted the two intercepts and the slope. Finally, non-significant predictors were trimmed from the model to examine the effects of removing any of the five individual interaction terms from this block of variables. At each of these steps, 
deviance statistics were calculated to determine if each change in the group of predictors significantly added to the prediction of the alliance intercepts and slope, and a likelihood ratio test was used to determine if the change in deviance between models was significant. A significance level of $p<.05$ was used for all HLM hypothesis tests. Results are reported for the full models with all controls, main effects, and interaction terms, and for the final trimmed models.

As described above, two HLM models were fitted. Model 1 examined the early alliance intercept and the slope in alliance simultaneously. In other words, at any given step, the same predictors were entered to predict early alliance as well as slope in alliance. Model 2 examined the middle alliance intercept.

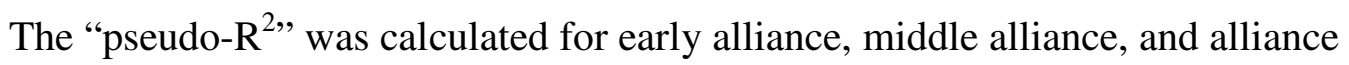
slope. This statistic represents the variance accounted for by the predictors (over $\&$ above what the time variable explained in the unconditional model) and is calculated by subtracting the variance of the conditional model from the variance of the unconditional model, then dividing the result by the variance of the unconditional model, and converting the number to a percentage by multiplying it by 100 .

All Level 2 variables were centered before they were entered in the HLM analyses. The two dichotomous control variables (treatment site \& treatment group) were centered around a mean of 0 , using -.5 and .5 for the two values. The four main effect variables (interpersonal distress, rigidity, control, \& affiliation) were mean-centered by subtracting the mean of the sample of 207 patients from each patient's value. The first interaction term (control by affiliation) was created by multiplying the two centered main effect variables. The remaining interaction terms (treatment by distress, rigidity, control, 
$\&$ affiliation, respectively) were created by multiplying the centered dichotomous variable with the centered main effect variables.

The fourth aim of the study was to explore differences between groups of patients with different alliance trajectories in terms of interpersonal distress, rigidity, and style. To do this, analyses proceeded in two steps. First, a group-based trajectory procedure from SAS (proc traj) was employed to identify distinct groups of individual alliance trajectories. The SAS analyses used the full sample of 220 patients who completed the pretreatment assessment, including the IIP.

Three models were constructed (fitting the data to two, three, or four groups) and the models were compared in terms of the Bayesian information criterion (BIC). As D'Unger, Land, McCall, and Nagin (1998) have recommended, the model with the BIC closest to 0 was deemed the best-fitting model. Next, ANOVAs were conducted to examine between-group differences on the following IIP-C variables: distress, rigidity, affiliation, control, hostile-dominance, hostile-submissiveness, friendly-dominance, and friendly-submissiveness. The .05 significance level was used for all ANOVA hypothesis tests. Tukey HSD tests were conducted to follow up on significant ANOVA results. Patient were pooled across the two treatment groups (CBT \& IPT) in order to provide sufficient statistical power to detect differences between the three trajectory groups. 


\section{CHAPTER 3}

\section{RESULTS}

The descriptive statistics for all study variables are presented in Table 2.

\section{HLM Analysis}

The estimated individual Level 1 trajectories for working alliance are shown in Figure 2. Results from the HLM analyses are described in detail below, and summarized in Tables 3 through 6. Although Model 1 examined the early alliance intercept and slope in alliance simultaneously, and Model 2 examined the middle alliance intercept, results are presented in order of early, middle, and slope in alliance because this order makes better conceptual sense for the three research questions of this study. Results are reported for the full models with all controls, main effects, and interaction terms, and for the final trimmed models.

\section{Level of Early Alliance (Week 2/Session 4)}

The unconditional model showed that, across the sample, the average level of early alliance was significantly different from $0\left(\gamma_{00}=18.07, t[206]=35.82, p<.001\right)$, with patients generally reporting strong alliances. The unconditional model also revealed significant variation among the individual alliance intercepts $\left(\tau_{00}=27.98, \chi^{2}[1,165]=\right.$ 353.67, $p<.001)$. The reliability of the intercept estimates was adequate (.54). Thus, modeling of the Level 1 alliance intercepts continued at Level 2.

The full conditional model showed a significant main effect of interpersonal distress on the early alliance intercept $\left(\gamma_{03}=-.32, t[195]=-2.497, p<.05\right)$; higher interpersonal distress at baseline was associated with lower early alliance. In addition, there was a significant main effect of interpersonal affiliation on the early alliance 
intercepts $\left(\gamma_{06}=.31, t[195]=2.097, p<.05\right)$; more baseline interpersonal problems of an affiliative nature were associated with better early alliance. No interaction terms significantly predicted the level of early alliance.

The full model for early alliance with all controls, main effect variables, and interaction terms (and the change in deviance after each modeling step) is shown in Table 3. Overall, the predictors in the full model accounted for $16.78 \%$ of the variance in the Level 1 intercepts for the early alliance (over $\&$ above what the time variable explained in the unconditional model).

Model trimming showed that two main effect variables (rigidity \& control) as well as each of the five interaction terms could be removed without a significant reduction in model fit (i.e., no significant change in deviance for the overall model), suggesting that they did not add significantly to the prediction of the early alliance nor change the effects of the other predictors.

The final trimmed model for early alliance is shown in Table 6 . As can be seen in the table, the most parsimonious model meeting the criteria of statistical significance for early alliance included only interpersonal distress and interpersonal affiliation (in addition to the two control variables). The deviance test compared this model to the model including only the two controls, and found that the addition of the two main effects variables resulted in a significant reduction in deviance, Chi-square $=13.72, \mathrm{df}=4, \mathrm{p}<$ 0.01 . The predictors in the model for accounted for $12.55 \%$ of the variance in the Level 1 intercepts. 


\section{Level of Middle Alliance (Week 10/Session 12)}

The unconditional model showed that, across the sample, the average level of middle alliance was significantly different from $0\left(\gamma_{00}=20.81, t[206]=42.34, p<.001\right)$, with patients generally reporting strong midtreatment alliances. The unconditional model also revealed significant variation among the individual intercepts for middle alliance $\left(\tau_{00}\right.$ $\left.=36.07, \chi^{2}[1,165]=723.71, p<.001\right)$. The reliability of the intercept estimates was high (.77). Thus, modeling of the Level 1 alliance intercepts continued at Level 2.

The full conditional model showed a significant main effect of interpersonal distress on the middle alliance intercepts $\left(\gamma_{03}=-.29, t[195]=-2.42, p<.05\right)$, with more baseline interpersonal distress associated with lower middle alliance. In addition, the conditional model showed a significant main effect of interpersonal affiliation on the middle alliance intercepts $\left(\gamma_{06}=.42, t[195]=2.91, p<.01\right)$; more baseline interpersonal problems of an affiliative nature were associated with better middle alliance.

The conditional model also showed significant interactions between treatment group and three of the interpersonal variables. First, there was an interaction between treatment group and interpersonal rigidity $\left(\gamma_{09}=1.095, t[195]=2.11, p<.05\right)$; higher levels of baseline rigidity were associated with lower middle alliance quality in CBT, but with better middle alliance quality in IPT, while lower levels of rigidity were associated with better alliance in CBT and lower alliance in IPT (see Figure 3$)^{4}$. The point of the cross-over interaction occurred around the mean level of rigidity for this sample, which was toward the lower end of the theoretical range of this variable.

Second, there was an interaction between treatment group and interpersonal control $\left(\gamma_{010}=.77, t[195]=2.01, p<.05\right)$; more baseline interpersonal problems of a 
controlling nature were associated with lower middle alliance quality in CBT, but with better middle alliance quality in IPT, while fewer problems with control were associated with better alliance in CBT and lower alliance in IPT (see Figure 4). The point of the cross-over interaction occurred around the mean level of control for this sample, which was toward the lower end of the theoretical range of this variable.

Third, there was an interaction between treatment group and interpersonal affiliation $\left(\gamma_{011}=-.82, t[195]=-2.78, p<.01\right)$; more baseline interpersonal problems of an affiliative nature were associated with better middle alliance in CBT, while affiliation was unrelated to alliance in IPT (see Figure 5).

The full model for middle alliance with all controls, main effect variables, and interaction terms (and the change in deviance after each modeling step) is shown in Table 4. Overall, the predictors in the full model accounted for $15.63 \%$ of the variance in the Level 1 intercepts for the middle alliance (over $\&$ above what the time variable explained in the unconditional model).

Examination of the Level 2 residuals revealed the presence of a multivariate outlier (see Figure 8). A sensitivity analysis, in which the model was fit without the inclusion of this case, revealed no important changes in the results except that the interaction of treatment by control was no longer significant.

Model trimming showed that two main effect variables (rigidity \& control), as well as two of the interaction terms (control by affiliation \& treatment by distress) could be removed from the model without a significant change in deviance, suggesting that they did not add significantly to the prediction of the middle alliance nor change the effects of the other predictors. 
The final trimmed model for middle alliance is shown in Table 6. As can be seen in the table, the most parsimonious model meeting the criteria of statistical significance for middle alliance included the four main effects (distress, rigidity, control, and affiliation) as well as three treatment group interactions (treatment by rigidity, treatment by control, and treatment by affiliation), in addition to the two control variables.

The deviance test compared this model to the model including only the two control variables, and found that the addition of the two main effects and three interactions resulted in a significant reduction in deviance, Chi-square $=24.16, \mathrm{df}=14, \mathrm{p}$ $<0.05$. The predictors in the final trimmed model for middle alliance accounted for $15.41 \%$ of the variance in the Level 1 intercepts.

\section{Change in Alliance}

The results for alliance slope were based on Model 1 which examined the early alliance intercept simultaneously. In other words, at any given step, the same predictors were entered to predict early alliance as well as slope in alliance. The data were centered at week 2 (but naturally the results for slope were identical in Model 2 which was centered at week 4).

The unconditional model showed that, across the sample, the average rate of change in alliance was significantly different from $0\left(\gamma_{10}=.34, t[206]=8.71, p<.001\right)$, showing that on average the alliance improved over time. There was also significant variation among the individual alliance slopes $\left(\tau_{10}=0.08, \chi^{2}[1, \mathrm{~N}=165]=239.14, p<\right.$ .001), showing that alliance changed differently for different individuals. Thus, predictors of alliance change were entered at Level 2. 
The conditional model showed a significant main effect of treatment group on the alliance slopes $\left(\gamma_{12}=.25, t[195]=3.22, p<.01\right)$, with faster growth in IPT than in CBT (see Figure 6). No other variables approached significance in the prediction of the slope in alliance. The full model with all controls, main effect variables, and interaction terms (and the change in deviance after each modeling step) is shown in Table 5. Overall, the predictors in this model accounted for $30.9 \%$ of the variance in the Level 1 alliance slopes (over and above what the time variable explained in the unconditional model).

The final trimmed model for rate of change in alliance is shown in Table 6. As can be seen in the table, the most parsimonious model meeting the criteria of statistical significance for middle alliance included only the two control variables. The deviance test compared this model to the unconditional model, and found that the addition of the two control variables resulted in a significant reduction in deviance, Chi-square $=13.86$, $\mathrm{df}=4, \mathrm{p}<0.01$. They accounted for $14.1 \%$ of the variance.

\section{Group-Based Trajectory Analysis}

Three different models were estimated (representing two, three, \& four groups of alliance trajectories) in order to determine the optimal number of groups. The BIC score was -1727.44 for the two-group model, -1720.72 for the three-group model, and -1728.71 for the four-group model. As per D'Unger et al.'s (1998) recommendation, the threegroup model best fit the data. Examination of the parameter estimates showed that the intercept term was significant, i.e., the initial alliance level was different from 0 for all three groups. For two of the three groups, the linear terms were significant as well, indicating that there was a significant change in alliance for these two groups. 
Figure 7 shows the trajectories of the three groups. The largest group (\#3)

comprised $50.5 \%$ of the sample, and showed a high initial alliance, as well as significant growth in alliance over time $($ intercept $=19.74$, S.E. $=.99, p<.001 ;$ slope $=5.75$, S.E. $=$ $.64, p<.001)$. The second-largest group (\#2) comprised $38.4 \%$ of the sample, and showed a lower initial alliance, as well as significant growth in alliance over time with a similar slope to group \#3 (intercept $=12.57$, S.E. $=1.64, p<.001$; slope $=4.53$, S.E. $=$ $1.07, p<.001)$. The smallest group (\#1) comprised $11.2 \%$ of the sample, and showed an even lower initial alliance and a slight, but statistically nonsignificant decline in alliance over time $($ intercept $=12.84$, S.E. $=3.36, p=.0002$; slope $=-3.30$, S.E. $=2.83, p=.24)$.

A one-way ANOVA was conducted with each of eight interpersonal variables in order to identify patient characteristics that distinguished membership in the three divergent trajectory groups. The omnibus ANOVA detected a significant difference between the three groups in terms of level of interpersonal distress, $F(2,217)=3.30, p<$ .05. The post hoc Tukey HSD test showed that interpersonal distress was significantly higher in Group $2(M=20.83, S D=4.34)$ than in Group $3(M=19.24, S D=4.21), p<$ $.05, d=.37$. The omnibus ANOVA further detected a significant difference between the three groups in terms of hostile-submissiveness, $F(2,217)=3.93, p<.05$. The post hoc Tukey HSD test showed that hostile-submissiveness was significantly higher in Group 2 $(M=55.21, S D=13.79)$ than in Group $3(M=49.38, S D=14.46), \mathrm{p}<.05, d=.41$. The statistics for all variables tested in the ANOVA are presented in Table 7.

Because the low number of patients in Group $1(\mathrm{~N}=18)$ affected the statistical power of the hypothesis testing, the ANOVA results reported above should be interpreted with caution. To determine the standardized mean differences among the three groups in 
terms of the interpersonal variables, effect sizes were calculated using the formula for Cohen's d. The effect size calculations found small to medium effects in the pairwise comparisons, as shown in Table 7. As can be seen in the table, patients in Group 1 (i.e., patients reporting low and stable alliances) were found to have lower affiliation scores than patients in Group $2(d=.41)$ and in Group $3(d=.54)$. In addition, they scored higher on hostile-dominance than patients in Group $2(d=.21)$ and patients in Group $3(d$ $=.54)$. 


\section{CHAPTER 4}

\section{DISCUSSION}

This study examined the predictors of level, rate of change, and pattern in therapeutic alliance within and across CBT and IPT treatments for BN. For the first three aims of the study, HLM was used to predict the level of the early and middle alliance, as well as the rate of change in alliance. The study found that the levels of early and middle alliance were both predicted by patient interpersonal distress (more baseline distress was associated with lower alliance) and by patient interpersonal affiliation (more baseline interpersonal problems of an affiliative nature were associated with better alliance). The present results are somewhat difficult to compare to previous studies in that different studies have used different variables from the IIP or IIP-C. However, the hypothesis that early alliance would be unrelated to interpersonal distress was not confirmed. This was in contrast to the findings by Constantino et al. (2005) who used regression analyses to examine the same dataset and to findings by Connolly Gibbons et al. (2003) who also found that early alliance was unrelated to level of interpersonal distress, but similar to Beretta et al., 2005. However, as expected, interpersonal distress was negatively associated with the alliance at midtreatment.

The hypothesis that affiliation would be positively associated with both early and middle alliance was confirmed. This result replicated the findings of several studies (e.g., Beretta et al., 2005; Muran et al., 1994; Nevo, 2002) and is consistent with studies that have linked cold, detached, or hostile interpersonal problems to poorer alliance (e.g., Connolly Gibbons et al., 2003; Paivio \& Bahr, 1998; Saunders, 2000). Nevo’s (2002) 
finding that higher levels of control were positively associated with the alliance was not replicated.

The present results make sense from a clinical perspective in that patients who have difficulty in their relationships with people in general seem to have more trouble establishing strong working alliances with their therapists. In addition, patients who tend to be highly affiliative, even though at extremes they may be too self-sacrificing and overly accommodating, seem to establish strong working alliances quite readily. It may be that an overly affiliative style leads to easy agreement on the tasks and goals of treatment ( $\&$ thus good alliance behavior) and/or that the patient's accommodating nature leads him or her to rate the alliance more positively. In either case, this finding may be consistent with Muran et al.'s (1994) notion that some aspects of the alliance may reflect general compliance.

The study also found that middle alliance quality was predicted by interactions between treatment group and three interpersonal variables. Most robustly, more baseline interpersonal problems of an affiliative nature were associated with better middle alliance in CBT, while affiliation was unrelated to alliance in IPT. Also, higher baseline levels of both interpersonal rigidity and control at were associated with lower middle alliance quality in CBT, but with better middle alliance quality in IPT, while lower levels of rigidity and control were associated with better alliance in CBT and lower alliance in IPT (though after deletion of a multivariate outlier, the result for treatment by control was no longer significant).

These results suggest that in CBT the alliance may be highly dependent on the patient's level of affiliation and, conversely, highly sensitive to patient rigidity, hostility, 
and coldness. Thus, as a highly directive treatment, CBT may be most suitable for patients with more affiliative, less controlling, and less rigid interpersonal style, as patients who are very rigid and controlling may perceive the alliance more negatively. IPT on the other hand places eating disorder symptoms within an interpersonal context and explicitly focuses on how the patient's interpersonal difficulties and deficits may be driving the eating disorder. Thus, with this focus, it may be that IPT allows therapists to effectively use interpersonal material as it manifests in the therapy relationship in the service of the treatment plan. This, in turn, could promote greater agreement on the task and goals of treatment despite potential interpersonal challenges. For example, low affiliation was negatively associated with the alliance in CBT, but unrelated to the alliance in IPT. Furthermore, it appears that in IPT a strong alliance can develop despite specific types of interpersonal problems, and can also withstand such problems as they emerge in therapy. This is less the case in CBT, which explicitly focuses on eating behavior and cognitions about weight and shape. Thus, in the face of difficult interpersonal issues, CBT therapists may have more difficulty implementing the specific treatment and responding to alliance problems. In fact, overall, the study found that rate of change in alliance was predicted by treatment group, with faster growth in IPT than in CBT.

Finally, for the fourth aim of the study, group-based trajectory analysis was used to detect groups of patients with similar alliance patterns over time (across the two treatment groups). The study found three divergent patterns of alliance development. Over half of the patients reported a high initial alliance followed by significant growth. A smaller group reported a lower (moderate level) initial alliance followed by significant 
growth, while the smallest group of patients reported even lower alliances with their therapists, and these ratings remained stable over time. The trajectory results are difficult to compare to previous studies because different studies have (a) found different types of clusters of alliance trajectories (e.g., high \& stable; high \& improving), (b) used quadratic modeling capable of detecting curvilinear trajectories (e.g., U-shaped patterns, vs. linear modeling), and/or (c) reported different types of statistics, such as slope, curve, and variability around the curve. Nevertheless, as in the study by Beretta et al. (2005), the present study showed that the least favorable alliance pattern (i.e., low \& stable alliances) was found in the smallest groups of patients. Also, the most favorable alliance pattern in the current study (high \& improving alliances) was the most predominant pattern, reported by $51 \%$ of the sample. This pattern resembled the second cluster found by Stiles et al. (2004), which was also the most predominant pattern, where patients reported relatively high and stable alliances with their therapists.

Furthermore, this study found significant group differences in terms of patient interpersonal characteristics. Specifically, patients with lower initial alliances followed by growth in alliance (Group 2) reported significantly more baseline interpersonal distress and more interpersonal problems related to hostile-submissiveness than patients with higher initial alliances (Group3). Thus, it appears that interpersonal distress, and particularly problems of a hostile-submissive nature, can have negative ramifications for the early relationship. However, over time, it appears that the alliance can tolerate such impacts and grow significantly stronger. Perhaps therapists who identify such patterns need to prepare for a difficult beginning, but can also predict that these types of patients will continue to work in treatment and will come to see the relationship as more positive 
(especially, perhaps, if working on interpersonal issues in IPT or evidencing reduction of problematic eating behaviors in CBT). It will be important to address in future research how patients' perception of the alliance over time covaries with changes in presenting problems.

The limitations of this study include the fact that only three alliance data points were available for the HLM and trajectory analyses, thus precluding the investigation of curvilinear models. Also, the presence of a multivariate outlier made it difficult to interpret some of the interactions in the HLM analysis, while reliability estimates for the early alliance were only adequate (.54). It should also be noted that the three groups found in the group-based trajectory analysis are not generalizable, but sample-dependent due to the semi-parametric nature of this type of analysis (D'Unger et al., 1998). Another limitation is the fact that only patient self-report data were available for the variables of interpersonal functioning and the alliance, which raises the problematic question of shared method variance. In addition, patient interpersonal style may influence how the alliance is perceived and rated such that patients with more submissive styles may rate the alliance more positively, suggesting that measures may in fact be assessing "compliance" as opposed to alliance. Finally, the conceptualization and measurement of the rigidity variable were problematic. In the HLM analyses, the coefficients for this variable changed sign depending on what other variables were in the model, suggesting problems with collinearity. Future studies can add to this literature by including more measurements of the alliance, thus allowing for quadratic modeling, and by striving for larger sample sizes that allow for analysis of alliance trajectories within the different types of treatments offered. Finally, measurements of the alliance from the perspectives 
of the therapist and/or an independent observer would add valuable information to future studies.

The study has important implications for clinical practice. First, it seems important for clinicians to carefully assess their patients' interpersonal functioning, especially with respect to overall distress and style. Specifically, when working with patients presenting with more interpersonal problems and/or with less affiliative (or more hostile) styles, therapists may need to attend more to the alliance than usual, starting early in treatment. Therapists should also consider how their particular theoretical orientation and use of specific techniques may interact with each patient's interpersonal profile. Specifically, when conducting CBT (or other types of active, directive treatments), clinicians should stay mindful of how patients with rigid interpersonal styles or problems with excessive control may perceive the relationship. Cognitive-behavioral therapists should keep in mind that in CBT the alliance may be highly sensitive to the patient's level of interpersonal affiliation, and that it may be most suitable for patients with somewhat submissive styles (at least for those presenting with bulimia nervosa, the population used for this study). This would be consistent with Muran et al.'s (1994) notion that it may be the complementarity of the two roles (a friendly-dominant therapist $\&$ a friendly-submissive patient) that is conducive to a strong alliance. These considerations are important in the continuing work to improve therapeutic relationships and ultimately treatment outcomes. 


\section{APPENDICES}

APPENDIX A

INVENTORY OF INTERPERSONAL PROBLEMS - CIRCUMPLEX SCALES

APPENDIX B

HELPING ALLIANCE QUESTIONNAIRE 
INVENTORY OF INTERPERSONAL PROBLEMS - CIRCUMPLEX SCALES

Please read the list below, and for each item, consider whether it has been a problem for you with respect to your peer relationships. Then, circle the number that describes how distressing that problem has been.

\section{The following are things you find hard to do with other people.}

\begin{tabular}{|c|c|c|c|c|c|}
\hline It is hard for me to: & $\begin{array}{l}\text { Not } \\
\text { at all }\end{array}$ & $\begin{array}{c}\text { A } \\
\text { little } \\
\text { bit }\end{array}$ & $\begin{array}{l}\text { Mode- } \\
\text { rately }\end{array}$ & $\begin{array}{l}\text { Quite } \\
\text { a bit }\end{array}$ & Extremely \\
\hline 1. Trust other people. & 1 & 2 & 3 & 4 & 5 \\
\hline 2. Say no to other people. & 1 & 2 & 3 & 4 & 5 \\
\hline 3. Join in on groups. & 1 & 2 & 3 & 4 & 5 \\
\hline 4. Keep things private from other people. & 1 & 2 & 3 & 4 & 5 \\
\hline 5. Let others know what I want. & 1 & 2 & 3 & 4 & 5 \\
\hline 6. Tell someone to stop bothering me. & 1 & 2 & 3 & 4 & 5 \\
\hline 7. Introduce myself to new people. & 1 & 2 & 3 & 4 & 5 \\
\hline 8. Confront people with problems that arise. & 1 & 2 & 3 & 4 & 5 \\
\hline 9. Be assertive with others. & 1 & 2 & 3 & 4 & 5 \\
\hline 10. Let others know when I am angry. & 1 & 2 & 3 & 4 & 5 \\
\hline 11. Make a long-term commitment to someone. & 1 & 2 & 3 & 4 & 5 \\
\hline 12. Be another person's boss. & 1 & 2 & 3 & 4 & 5 \\
\hline 13. Be aggressive towards others. & 1 & 2 & 3 & 4 & 5 \\
\hline 14. Socialize with others. & 1 & 2 & 3 & 4 & 5 \\
\hline 15. Show affection to people. & 1 & 2 & 3 & 4 & 5 \\
\hline 16. Get along with other people. & 1 & 2 & 3 & 4 & 5 \\
\hline 17. Understand another person's point of view. & 1 & 2 & 3 & 4 & 5 \\
\hline 18. Express my feelings to other people directly. & 1 & 2 & 3 & 4 & 5 \\
\hline 19. Be firm when I need to be. & 1 & 2 & 3 & 4 & 5 \\
\hline 20. Experience a feeling of love for someone else. & 1 & 2 & 3 & 4 & 5 \\
\hline 21. Set limits on other people. & 1 & 2 & 3 & 4 & 5 \\
\hline 22. Be supportive of another person's goals. & 1 & 2 & 3 & 4 & 5 \\
\hline 23. Feel close to other people. & 1 & 2 & 3 & 4 & 5 \\
\hline 24. Really care about another person's problems. & 1 & 2 & 3 & 4 & 5 \\
\hline 25. Argue with another person. & 1 & 2 & 3 & 4 & 5 \\
\hline 26. Spend time alone. & 1 & 2 & 3 & 4 & 5 \\
\hline 27. Give a gift to another person. & 1 & 2 & 3 & 4 & 5 \\
\hline 28. Let myself feel angry at someone I like. & 1 & 2 & 3 & 4 & 5 \\
\hline 29. Put somebody else's needs before my own. & 1 & 2 & 3 & 4 & 5 \\
\hline 30. Stay out of another person's business. & 1 & 2 & 3 & 4 & 5 \\
\hline 31. Take instructions from people in authority. & 1 & 2 & 3 & 4 & 5 \\
\hline 32. Feel good about another person's happiness. & 1 & 2 & 3 & 4 & 5 \\
\hline 33. Ask other people to get together socially with me. & 1 & 2 & 3 & 4 & 5 \\
\hline 34. Feel angry at other people. & 1 & 2 & 3 & 4 & 5 \\
\hline 35. Open up and share my feelings with others. & 1 & 2 & 3 & 4 & 5 \\
\hline 36. Forgive someone I have been angry with. & 1 & 2 & 3 & 4 & 5 \\
\hline 37. Attend to my needs when someone else is upset. & 1 & 2 & 3 & 4 & 5 \\
\hline 38. Be assertive w/o worrying about other's feelings. & 1 & 2 & 3 & 4 & 5 \\
\hline 39. Be self-confident around other people. & 1 & 2 & 3 & 4 & 5 \\
\hline
\end{tabular}




\begin{tabular}{|l|c|c|c|c|c|}
\hline \multicolumn{1}{|c|}{ The following are things you do too much. } & $\begin{array}{c}\text { Not at } \\
\text { all }\end{array}$ & $\begin{array}{c}\mathbf{A} \\
\text { little } \\
\text { bit }\end{array}$ & $\begin{array}{c}\text { Mode- } \\
\text { rately }\end{array}$ & $\begin{array}{c}\text { Quite } \\
\text { a bit }\end{array}$ & Extremely \\
\hline 40. I fight with other people too much. & 1 & 2 & 3 & 4 & 5 \\
\hline $\begin{array}{l}\text { 41. I feel too responsible for solving other's } \\
\text { problems. }\end{array}$ & 1 & 2 & 3 & 4 & 5 \\
\hline 42. I am too easily persuaded by others. & 1 & 2 & 3 & 4 & 5 \\
\hline 43. I open up too much to people. & 1 & 2 & 3 & 4 & 5 \\
\hline 44. I am too independent. & 1 & 2 & 3 & 4 & 5 \\
\hline 45. I am too aggressive towards other people. & 1 & 2 & 3 & 4 & 5 \\
\hline 46. I try to please other people too much. & 1 & 2 & 3 & 4 & 5 \\
\hline 47. I clown around too much. & 1 & 2 & 3 & 4 & 5 \\
\hline 48. I want to be noticed too much. & 1 & 2 & 3 & 4 & 5 \\
\hline 49. I trust other people too much. & 1 & 2 & 3 & 4 & 5 \\
\hline 50. I try to control other people too much. & 1 & 2 & 3 & 4 & 5 \\
\hline $\begin{array}{l}\text { 51. I put other people's needs before my own } \\
\text { too much. }\end{array}$ & 1 & 2 & 3 & 4 & 5 \\
\hline 52. I try to change other people too much. & 1 & 2 & 3 & 4 & 5 \\
\hline 53. I am too gullible. & 1 & 2 & 3 & 4 & 5 \\
\hline 54. I am overly generous to other people. & 1 & 2 & 3 & 4 & 5 \\
\hline 55. I am afraid of other people. & 1 & 2 & 3 & 4 & 5 \\
\hline 56. I am too suspicious of other people. & 1 & 2 & 3 & 4 & 5 \\
\hline $\begin{array}{l}\text { 57. I manipulate other people too much to get } \\
\text { what I want. }\end{array}$ & 1 & 2 & 3 & 4 & 5 \\
\hline 58. I tell personal things to other people too much. & 1 & 2 & 3 & 4 & 5 \\
\hline 59. I argue with other people too much. & 1 & 2 & 3 & 4 & 5 \\
\hline 60. I keep other people at a distance too much. & 2 & 3 & 4 & 5 \\
\hline $\begin{array}{l}\text { 61. I let other people take advantage of me } \\
\text { too much. }\end{array}$ & 1 & 2 & 3 & 4 & 5 \\
\hline $\begin{array}{l}\text { 62. I feel embarrassed in front of other } \\
\text { people too much. }\end{array}$ & & & 3 & 4 & 5 \\
\hline $\begin{array}{l}\text { 63. I am affected by another person's unhappiness } \\
\text { too much. }\end{array}$ & 1 & 2 & 3 & 4 & 5 \\
\hline $\begin{array}{l}\text { 64. I want to get revenge against other } \\
\text { people too much. }\end{array}$ & 1 & & & 5 \\
\hline
\end{tabular}

Note. In the original study by Agras et al. (2000), patients completed the full 127-item Inventory of Interpersonal Problems (IIP), using a Likert scale ranging from 1 to 5. Data for the current study are based on a subset of these 127 items, i.e., the 64 items of the IIPC. The actual 64-item IIP-C uses a Likert scale ranging from 0 to 4. 


\section{APPENDIX B}

\section{HELPING ALLIANCE QUESTIONNAIRE}

Below are listed a variety of ways that one person may feel or behavior in relation to another person. Please consider each statement with reference to your present relationship with your therapist. Indicated how strongly you feel that it is true or not true in this relationship.

\section{Strongly feel it's true}

2 Feel it's true

1 Feel it's probably true or more true than untrue

$-1 \quad$ Feel it's probably not true or more untrue and true

$-2 \quad$ Feel it's untrue

$-3 \quad$ Strongly feel it's untrue

1. I believe that my therapist is helping me.

2. I believe that the treatment is helping me.

3. I have obtained some new understanding.

4. I have been feeling better recently.

5. I can already see that I will eventually work out the problems I came to treatment for.

6. I feel I can depend upon the therapist.

7. I feel the therapist understands me.

8. I feel the therapist wants me to achieve my goals.

9. I feel I am working together with the therapist in a joint effort.

10. I believe we have similar ideas about the nature of my problems.

11. I feel now that I can understand myself and deal with myself on my own (that is, even if the therapist and I were no longer meeting for treatment appointments). 


\section{Footnotes}

${ }^{1}$ Over time, the labels associated with the eight scales have changed slightly.

Table 1 provides a cross-reference of the different labels, as well as subscale descriptions.

${ }^{2}$ In the original study by Agras et al. (2000), patients completed the full 127-item Inventory of Interpersonal Problems (IIP), using a Likert scale ranging from 1 to 5. Data for the current study are based on a subset of these 127 items, i.e., the 64 items of the IIPC. The actual 64-item IIP-C uses a Likert scale ranging from 0 to 4 .

${ }^{3}$ Item-level data for the HAq at week 20 was not accessible for this study, so internal consistency reliability could not be calculated for the last administration of the HAq.

${ }^{4}$ The graphed values for all three interactions represent the centered values of the entire range of each of the predictors (rigidity, control, \& affiliation) on the horizontal axis and the range of 10-30 of alliance on the vertical axis. 
Table 1

Cross-Reference Table for Labels and Descriptions of the Subscales of the Inventory of

Interpersonal Problems - Circumplex Scales (IIP-C)

\begin{tabular}{|c|c|c|}
\hline Subscales * & Descriptions * & Subscales** \\
\hline Domineering & $\begin{array}{l}\text { High scorers report problems related to controlling, } \\
\text { manipulating, aggressing toward, and trying to change } \\
\text { others. }\end{array}$ & $\begin{array}{l}\text { Domineering/ } \\
\text { Controlling }\end{array}$ \\
\hline Vindictive & $\begin{array}{l}\text { High scorers report problems related to distrust and } \\
\text { suspicion of others and an inability to care about others' } \\
\text { needs and happiness. }\end{array}$ & $\begin{array}{l}\text { Vindictive/ } \\
\text { Self-centered }\end{array}$ \\
\hline Cold & $\begin{array}{l}\text { High scorers report an inability to express affection toward } \\
\text { and to feel love for another person, difficulty making long- } \\
\text { term commitments to others, and an inability to be generous } \\
\text { to, get along with, and forgive others. }\end{array}$ & $\begin{array}{c}\text { Cold/ } \\
\text { Distant }\end{array}$ \\
\hline $\begin{array}{l}\text { Socially } \\
\text { Avoidant }\end{array}$ & $\begin{array}{l}\text { High scorers feel anxious and embarrassed in the presence } \\
\text { of other and have difficulty initiating social interactions, } \\
\text { expressing feelings, and socializing with others. }\end{array}$ & $\begin{array}{l}\text { Socially } \\
\text { Inhibited }\end{array}$ \\
\hline Nonassertive & $\begin{array}{l}\text { High scorers report difficulty making their needs known to } \\
\text { others, discomfort in authoritative roles, and an inability to } \\
\text { be firm with and assertive toward others. }\end{array}$ & Nonassertive \\
\hline Exploitable & $\begin{array}{l}\text { High scorers find it difficult to feel anger for fear of } \\
\text { offending others. They describe themselves as gullible and } \\
\text { readily taken advantage of by others. }\end{array}$ & $\begin{array}{c}\text { Overly } \\
\text { Accommodating }\end{array}$ \\
\hline $\begin{array}{l}\text { Overly } \\
\text { Nurturant }\end{array}$ & $\begin{array}{l}\text { High scorer report that they try too hard to please others } \\
\text { and are too generous, trusting, caring, and permissive in } \\
\text { dealing with others. }\end{array}$ & Self-sacrificing \\
\hline Intrusive & $\begin{array}{l}\text { High scorers are inappropriately self-disclosing, attention } \\
\text { seeking, and find it difficult to spend time alone. }\end{array}$ & $\begin{array}{l}\text { Intrusive/ } \\
\text { Needy }\end{array}$ \\
\hline
\end{tabular}

Note. The IIP-C was developed by Alden, Wiggins, \& Pincus (1990). * Subscale labels and descriptions from Alden et al. (1990). ** Subscale labels from Horowitz, Alden, Wiggins, \& Pincus (2000). 
Table 2

Descriptive Statistics for Alliance and Interpersonal Variables

Measure
Alliance Variables (HAq)

Early Alliance

Middle Alliance

Late Alliance

Interpersonal Variables (IIP-C)

Structural Scores

Distress

Rigidity

Control

Affiliation

Quadrant Scores

Friendly-Dominance

Friendly-Submissiveness

Hostile-Dominance

Hostile-Submissiveness

Scale Scores

Domineering

Vindictive

Cold

Socially Inhibited
197

18.04

160

158

$$
21.40
$$

24.42

9.11

$-19$

$-.8$

$-.15$

33

33

$-.623$

$-1.067$

$-1.689$

Skew 


\begin{tabular}{lcccccc} 
Nonassertive & 207 & 23.94 & 7.81 & 8 & 40 & -.165 \\
Overly Accommodating & 207 & 23.02 & 6.95 & 8 & 39 & .163 \\
Self-Sacrificing & 207 & 23.13 & 6.82 & 10 & 40 & .164 \\
Intrusive & 207 & 17.86 & 5.46 & 8 & 33 & .456 \\
\hline
\end{tabular}

Note. $\mathrm{HAq}=$ The Helping Alliance Inventory. IIP-C $=$ The Inventory of Interpersonal Problems -

Circumplex Scales. Early alliance was measured following session 4 during week 2, middle alliance was measured following session 12 during week 10, and late alliance was measured following session 19 during week 20 . 
Table 3

Predicting Early Alliance (Week 2) with Interpersonal Variables: Standardized Coefficients

\begin{tabular}{|c|c|c|c|c|}
\hline Alliance & $\begin{array}{c}\text { Step 1: } \\
\text { Unconditional }\end{array}$ & $\begin{array}{c}\text { Step 2: } \\
\text { Controls }\end{array}$ & $\begin{array}{c}\text { Step 3: } \\
\text { Controls, } \\
\text { Main Effects }\end{array}$ & $\begin{array}{c}\text { Step 4: } \\
\text { Controls, } \\
\text { Main Effects, } \\
\text { Interactions }\end{array}$ \\
\hline Intercept & $18.07(0.50) * * *$ & $18.05(0.50) * * *$ & $18.05(0.50) * * *$ & $18.07(0.50) * * *$ \\
\hline \multicolumn{5}{|l|}{ Controls } \\
\hline $\begin{array}{l}\text { Treatment Group } \\
(0=\mathrm{CBT}, 1=\mathrm{IPT})\end{array}$ & & $-0.40(0.99)$ & $-0.54(0.978)$ & $-0.52(0.97)$ \\
\hline Treatment Site & & $1.93(0.99)$ & $1.59(0.98)$ & $1.395(0.98)$ \\
\hline \multicolumn{5}{|l|}{ Main Effects } \\
\hline Interpersonal Distress & & & $-0.32(0.13) *$ & $-0.32(0.13) *$ \\
\hline Interpersonal Rigidity & & & $0.09(0.26)$ & $-0.02(0.27)$ \\
\hline Interpersonal Affiliation & & & $0.26(0.15)^{\mathrm{a}}$ & $0.31(0.15) *$ \\
\hline Interpersonal Control & & & $0.02(0.19)$ & $-0.06(0.199)$ \\
\hline \multicolumn{5}{|l|}{ Interaction Terms } \\
\hline Control x Affiliation & & & & $0.01(0.04)$ \\
\hline Treatment Group x Distress & & & & $0.18(0.25)$ \\
\hline Treatment Group x Rigidity & & & & $0.46(0.54)$ \\
\hline Treatment Group x Affiliation & & & & $-0.496(0.30)$ \\
\hline Treatment Group x Control & & & & $0.40(0.40)$ \\
\hline \multicolumn{5}{|l|}{ Variance Components } \\
\hline Residual Variance & 27.98 & 27.17 & 24.44 & 23.29 \\
\hline Level 1 Variance & 27.63 & 27.33 & 27.37 & 27.57 \\
\hline Deviance (\# of Parameters) & $3506.75(6)$ & $3492.89(10)$ & $3478.08(18)$ & $3466.46(28)$ \\
\hline Deviance Tests (Change in $\chi^{2}$ ) & & $\begin{array}{c}\chi^{2}=13.86 \\
d f=4 \\
p=.008\end{array}$ & $\begin{array}{c}\chi^{2}=14.81 \\
d f=8 \\
p=.062\end{array}$ & $\begin{array}{c}\chi^{2}=11.63 \\
d f=10 \\
p=.31\end{array}$ \\
\hline
\end{tabular}

Note. $*=\mathrm{p}<.05, * *=\mathrm{p}<.01, * * *=\mathrm{p}<.001$. a) The four main effect variables (distress, rigidity, control, \& affiliation) were examined individually and in all possible combinations of two, three, and four variables in order to determine whether they significantly predicted the early alliance, and whether any combination of the four variables showed problems with collinearity. Across the analyses, affiliation was a consistent and significant predictor of early 
alliance, except in the flagged combination with the three other variables (step 3), possibly due to the presence of the problematic rigidity variable. 
Table 4

Predicting Middle Alliance (Week 10) with Interpersonal Variables: Standardized Coefficients

\begin{tabular}{|c|c|c|c|c|}
\hline Alliance & $\begin{array}{c}\text { Step 1: } \\
\text { Unconditional }\end{array}$ & $\begin{array}{l}\text { Step 2: } \\
\text { Controls }\end{array}$ & $\begin{array}{c}\text { Step 3: } \\
\text { Controls, } \\
\text { Main Effects }\end{array}$ & $\begin{array}{c}\text { Step 4: } \\
\text { Controls, } \\
\text { Main Effects, } \\
\text { Interactions } \\
\end{array}$ \\
\hline Intercept & $20.81(0.49) * * *$ & $20.78(0.49) * * *$ & $20.74(0.48) * * *$ & $20.83(0.48) * * *$ \\
\hline \multicolumn{5}{|l|}{ Controls } \\
\hline $\begin{array}{l}\text { Treatment Group } \\
(0=\mathrm{CBT}, 1=\mathrm{IPT})\end{array}$ & & $1.51(0.97)$ & $1.38(0.95)$ & $1.45(0.93)$ \\
\hline Treatment Site & & $1.54(0.97)$ & $1.28(0.95)$ & $0.95(0.94)$ \\
\hline \multicolumn{5}{|l|}{ Main Effects } \\
\hline Interpersonal Distress & & & $-0.30(0.12) *$ & $-0.29(0.12) *$ \\
\hline Interpersonal Rigidity & & & $-0.03(0.25)$ & $-0.16(0.26)$ \\
\hline Interpersonal Affiliation & & & $0.35(0.14) *$ & $0.42(0.14) * *$ \\
\hline Interpersonal Control & & & $-0.097(0.19)$ & $-0.21(0.19)$ \\
\hline \multicolumn{5}{|l|}{ Interaction Terms } \\
\hline Control x Affiliation & & & & $0.03(0.04)$ \\
\hline Treatment Group x Distress & & & & $0.03(0.24)$ \\
\hline Treatment Group x Rigidity & & & & $1.10(0.52) *$ \\
\hline Treatment Group x Affiliation & & & & $-0.82(0.30) * *$ \\
\hline Treatment Group x Control & & & & $0.77(0.38) *$ \\
\hline \multicolumn{5}{|l|}{ Variance Components } \\
\hline Residual Variance & 36.07 & 35.17 & 32.09 & 30.43 \\
\hline Level 1 Variance & 27.63 & 27.33 & 27.37 & 27.57 \\
\hline Deviance (\# of Parameters) & $3506.75(6)$ & $3492.89(10)$ & $3478.08(18)$ & $3466.46(28)$ \\
\hline Deviance Tests (Change in $\chi^{2}$ ) & & $\begin{array}{c}\chi^{2}=13.86 \\
d f=4 \\
p=.008\end{array}$ & $\begin{array}{c}\chi^{2}=14.81 \\
d f=8 \\
p=.062\end{array}$ & $\begin{array}{c}\chi^{2}=11.63 \\
d f=10 \\
p=.31\end{array}$ \\
\hline
\end{tabular}

Note. $*=\mathrm{p}<.05, * *=\mathrm{p}<.01, * * *=\mathrm{p}<.001$. 
Table 5

Predicting Rate of Change in Alliance with Interpersonal Variables: Standardized Coefficients

\begin{tabular}{|c|c|c|c|c|}
\hline Alliance & $\begin{array}{c}\text { Step 1: } \\
\text { Unconditional }\end{array}$ & $\begin{array}{l}\text { Step 2: } \\
\text { Controls }\end{array}$ & $\begin{array}{c}\text { Step 3: } \\
\text { Controls, } \\
\text { Main Effects }\end{array}$ & $\begin{array}{c}\text { Step 4: } \\
\text { Controls, } \\
\text { Main Effects, } \\
\text { Interactions } \\
\end{array}$ \\
\hline Intercept & $0.34(0.04) * * *$ & $0.34(0.04) * * *$ & $0.34(0.04) * * *$ & $0.34(0.04) * * *$ \\
\hline \multicolumn{5}{|l|}{ Controls } \\
\hline $\begin{array}{l}\text { Treatment Group } \\
(0=\mathrm{CBT}, 1=\mathrm{IPT})\end{array}$ & & $0.24(0.08) * *$ & $0.24(0.08) * *$ & $0.25(0.08) * *$ \\
\hline Treatment Site & & $-0.05(0.08)$ & $-0.04(0.08)$ & $-0.06(0.08)$ \\
\hline \multicolumn{5}{|l|}{ Main Effects } \\
\hline Interpersonal Distress & & & $0.003(0.01)$ & $0.003(0.01)$ \\
\hline Interpersonal Rigidity & & & $-0.01(0.02)$ & $-0.02(0.02)$ \\
\hline Interpersonal Affiliation & & & $0.01(0.01)$ & $0.01(0.01)$ \\
\hline Interpersonal Control & & & $-0.01(0.02)$ & $-0.02(0.02)$ \\
\hline \multicolumn{5}{|l|}{ Interaction Terms } \\
\hline Control x Affiliation & & & & $0.003(0.003)$ \\
\hline Treatment Group x Distress & & & & $-0.02(0.02)$ \\
\hline Treatment Group x Rigidity & & & & $0.08(0.04)$ \\
\hline Treatment Group x Affiliation & & & & $-0.04(0.02)$ \\
\hline Treatment Group x Control & & & & $0.05(0.03)$ \\
\hline \multicolumn{5}{|l|}{ Variance Components } \\
\hline Residual Variance & .08 & .07 & .06 & .05 \\
\hline Level 1 Variance & 27.63 & 27.33 & 27.37 & 27.57 \\
\hline Deviance (\# of Parameters) & $3506.75(6)$ & $3492.89(10)$ & $3478.08(18)$ & $3466.46(28)$ \\
\hline Deviance Tests (Change in $\chi^{2}$ ) & & $\begin{array}{c}\chi^{2}=13.86 \\
d f=4 \\
p=.008\end{array}$ & $\begin{array}{c}\chi^{2}=14.81 \\
d f=8 \\
p=.062\end{array}$ & $\begin{array}{c}\chi^{2}=11.63 \\
d f=10 \\
p=.31\end{array}$ \\
\hline
\end{tabular}

Note. $*=\mathrm{p}<.05, * *=\mathrm{p}<.01, * * *=\mathrm{p}<.001$. 
Table 6

Final Trimmed Models for Predicting Early and Middle Alliance, and Rate of Change in Alliance, with Interpersonal Variables: Standardized Coefficients

\begin{tabular}{|c|c|c|c|}
\hline Alliance & $\begin{array}{c}\text { Early } \\
\text { Alliance } \\
\text { (Week 2) }\end{array}$ & $\begin{array}{c}\text { Middle } \\
\text { Alliance } \\
\text { (Week 10) }\end{array}$ & $\begin{array}{c}\text { Rate of } \\
\text { Change in } \\
\text { Alliance }\end{array}$ \\
\hline Intercept & $18.04(0.49)^{* * *}$ & $20.75(0.47) * * *$ & $0.34(0.04) * * *$ \\
\hline \multicolumn{4}{|l|}{ Controls } \\
\hline $\begin{array}{l}\text { Treatment Group } \\
(0=\mathrm{CBT}, 1=\mathrm{IPT})\end{array}$ & $-0.55(0.97)$ & $1.45(0.93)$ & $0.24(0.08) * *$ \\
\hline Treatment Site & $1.61(0.98)$ & $0.97(0.94)$ & $-0.05(0.08)$ \\
\hline \multicolumn{4}{|l|}{ Main Effects } \\
\hline Interpersonal Distress & $-0.30(0.11) * *$ & $-0.30(0.12) *$ & - \\
\hline Interpersonal Rigidity & - & $-0.17(0.25)$ & - \\
\hline Interpersonal Affiliation & $0.28(0.13) *$ & $0.42(0.14) * *$ & - \\
\hline Interpersonal Control & - & $-0.20(0.19)$ & - \\
\hline Interaction Terms & & & - \\
\hline Control x Affiliation & - & - & - \\
\hline Treatment Group x Distress & - & - & - \\
\hline Treatment Group x Rigidity & - & $1.00(0.50) *$ & - \\
\hline Treatment Group x Affiliation & - & $-0.77(0.29) * *$ & - \\
\hline Treatment Group x Control & - & $0.70(0.38)$ & - \\
\hline \multicolumn{4}{|l|}{$\begin{array}{c}\text { Variance Components } \\
\text { Residual Variance }\end{array}$} \\
\hline Intercept & 24.47 & 30.51 & 27.17 \\
\hline Slope & 0.07 & 0.06 & 0.07 \\
\hline Level 1 Variance & 27.37 & 27.44 & 27.33 \\
\hline Deviance (\# of Parameters) & $3479.17(14)$ & $3468.73(24)$ & $3492.89(10)$ \\
\hline
\end{tabular}

Note. $*=\mathrm{p}<.05, * *=\mathrm{p}<.01, * * *=\mathrm{p}<.001$. Note that Model 1 predicted early alliance and rate of change in alliance, while Model 2 predicted middle alliance. 
Table 7

Descriptive Statistics and Group Differences for Interpersonal Variables in Three Alliance Trajectory Groups

\begin{tabular}{|c|c|c|c|c|c|c|c|c|c|c|c|}
\hline \multirow[t]{2}{*}{ Interpersonal Variables } & \multicolumn{2}{|c|}{$\begin{array}{c}\text { Group } 1 \\
\mathrm{~N}=18\end{array}$} & \multicolumn{2}{|c|}{$\begin{array}{c}\text { Group } 2 \\
\mathrm{~N}=80\end{array}$} & \multicolumn{2}{|c|}{$\begin{array}{l}\text { Group } 3 \\
\mathrm{~N}=122\end{array}$} & \multirow[t]{2}{*}{$\begin{array}{l}\text { ANOVA } \\
\mathrm{F}\end{array}$} & \multirow[t]{2}{*}{$\begin{array}{c}\text { Tukey's HSD } \\
\text { Group Differences }\end{array}$} & \multicolumn{3}{|c|}{$\begin{array}{l}\text { Cohen's d } \\
\text { Effect Sizes }\end{array}$} \\
\hline & $M$ & $S D$ & $M$ & $S D$ & $M$ & $S D$ & & & $\begin{array}{l}\text { Groups } \\
1 \text { and } 2\end{array}$ & $\begin{array}{l}\text { Groups } \\
1 \text { and } 3\end{array}$ & $\begin{array}{l}\text { Groups } \\
2 \text { and } 3\end{array}$ \\
\hline \multicolumn{12}{|l|}{ Structural Scores } \\
\hline Distress & 19.81 & 4.94 & 20.83 & 4.34 & 19.24 & 4.21 & $3.30 *$ & Group $2>$ Group 3 & 0.22 & 0.12 & 0.37 \\
\hline Rigidity & 5.47 & 3.19 & 6.85 & 3.46 & 6.19 & 3.41 & 1.58 & & 0.42 & 0.22 & 0.19 \\
\hline Control & -3.05 & 4.28 & -4.86 & 4.23 & -3.82 & 4.35 & 2.03 & & 0.43 & 0.18 & 0.24 \\
\hline Affiliation & .0053 & 3.71 & 1.57 & 3.89 & 1.96 & 3.57 & 2.21 & & 0.41 & 0.54 & 0.10 \\
\hline \multicolumn{12}{|l|}{ Quadrant Scores } \\
\hline Friendly-Dominance & 43.56 & 10.69 & 45.93 & 11.89 & 44.12 & 10.72 & .74 & & 0.21 & 0.05 & 0.16 \\
\hline Friendly-Submissiveness & 52.10 & 17.52 & 59.29 & 16.38 & 54.44 & 15.00 & 2.90 & & 0.42 & 0.14 & 0.31 \\
\hline Hostile-Dominance & 43.48 & 11.10 & 41.14 & 10.85 & 38.13 & 11.25 & 2.94 & & 0.21 & 0.48 & 0.27 \\
\hline Hostile-Submissiveness & 52.14 & 17.29 & 55.21 & 13.79 & 49.38 & 14.46 & $3.93 *$ & Group $2>$ Group 3 & 0.20 & 0.17 & 0.41 \\
\hline
\end{tabular}

Note. ${ }^{*} \mathrm{p}<.05$ for the omnibus ANOVA tests. 
Figure 1. Circumplex model of interpersonal problems. Adapted from Ruiz et al. (2004).

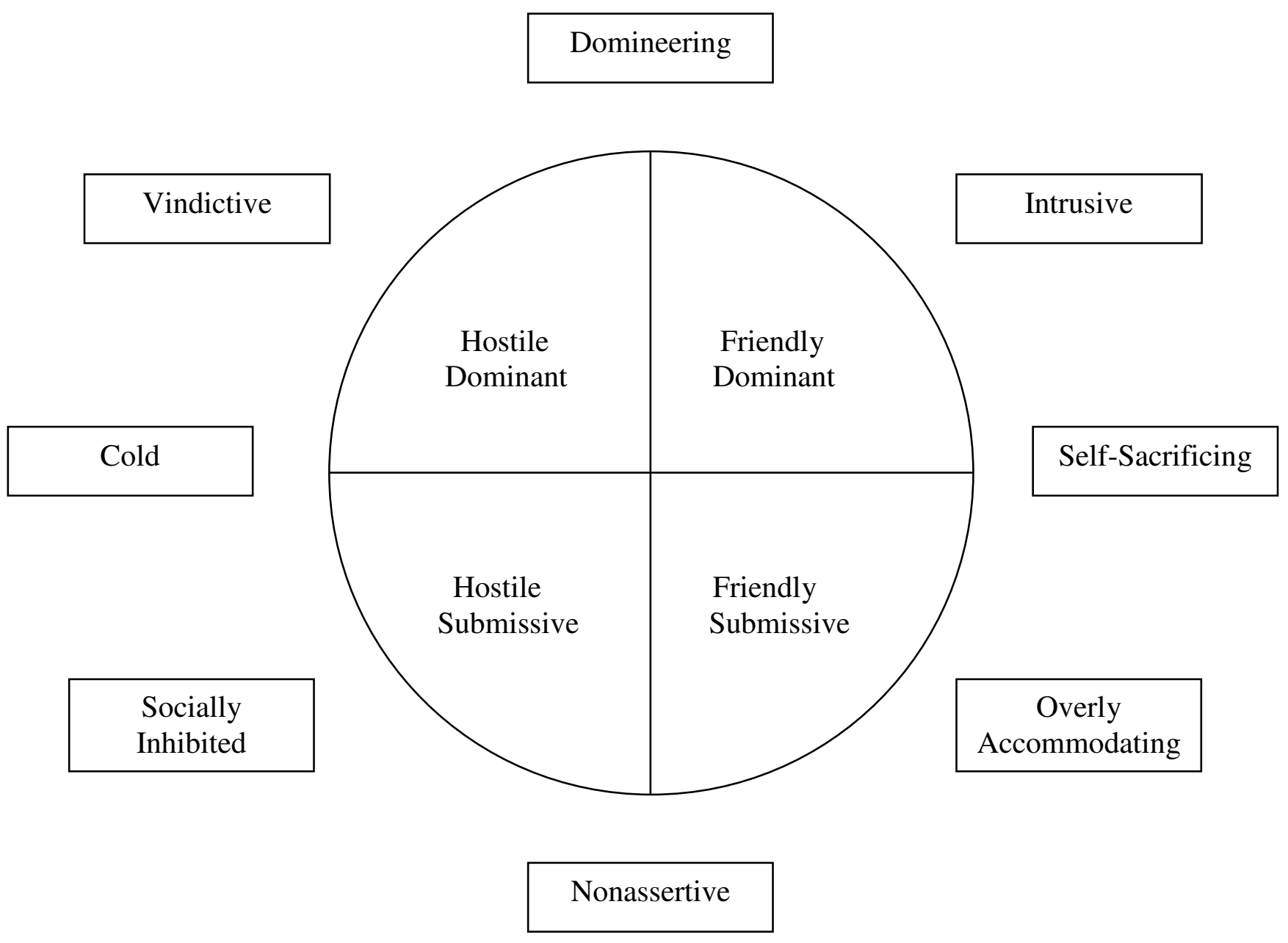


Figure 2. Unconditional HLM trajectories for working alliance.

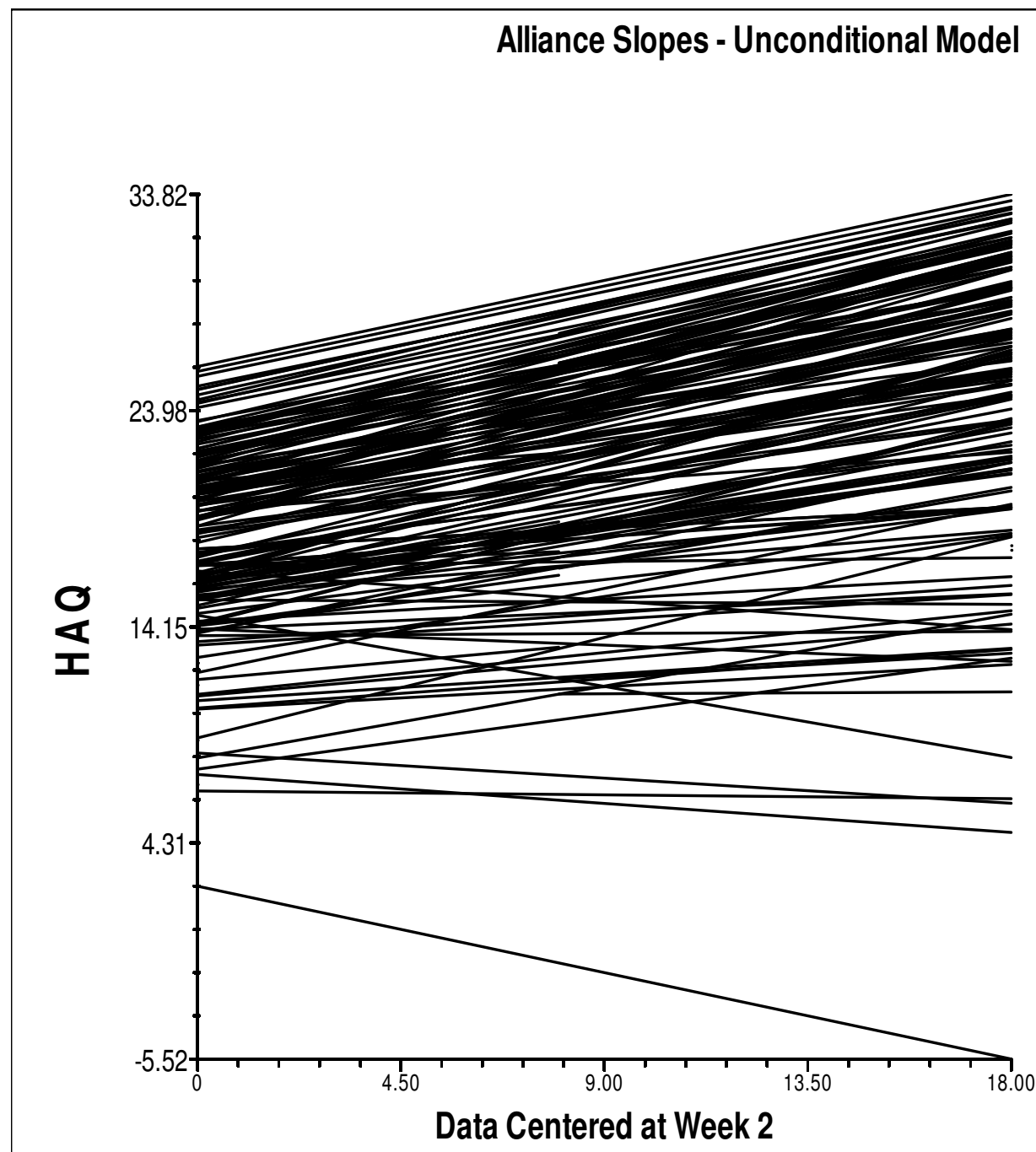


Figure 3. Relation between alliance and interpersonal rigidity displayed for two treatment groups.

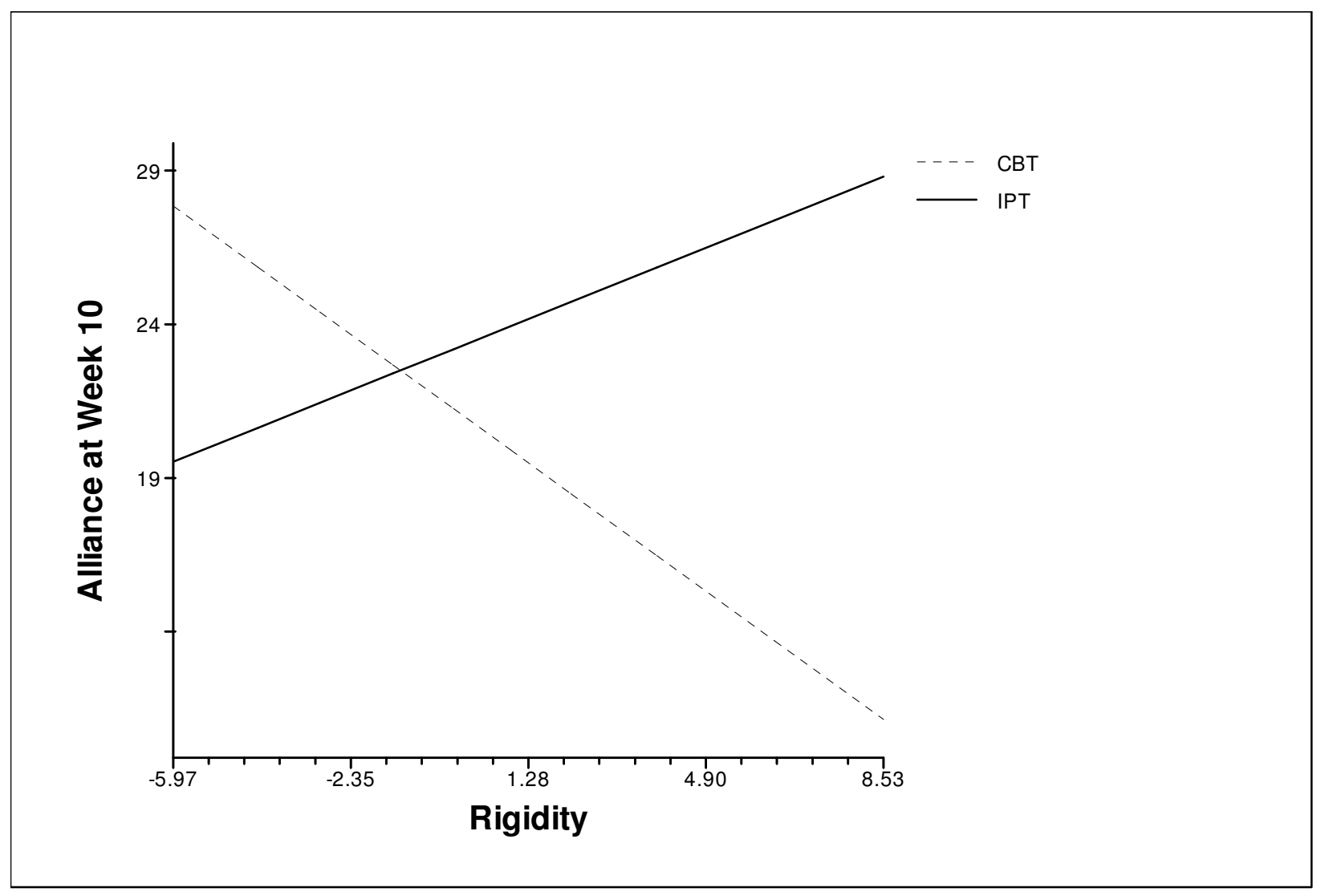


Figure 4. Relation between alliance and interpersonal control displayed for two treatment groups.

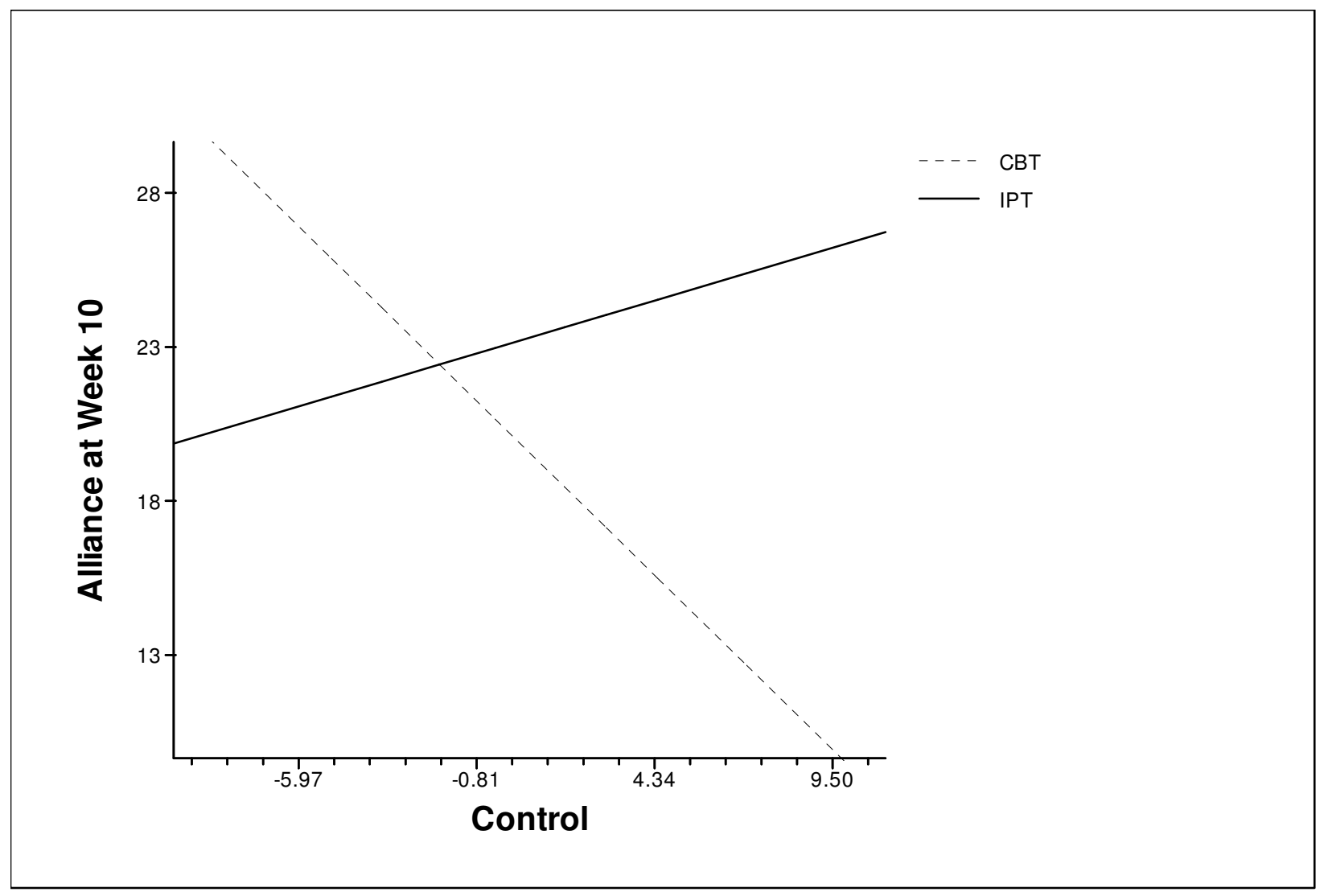


Figure 5. Relation between alliance and interpersonal affiliation displayed for two treatment groups.

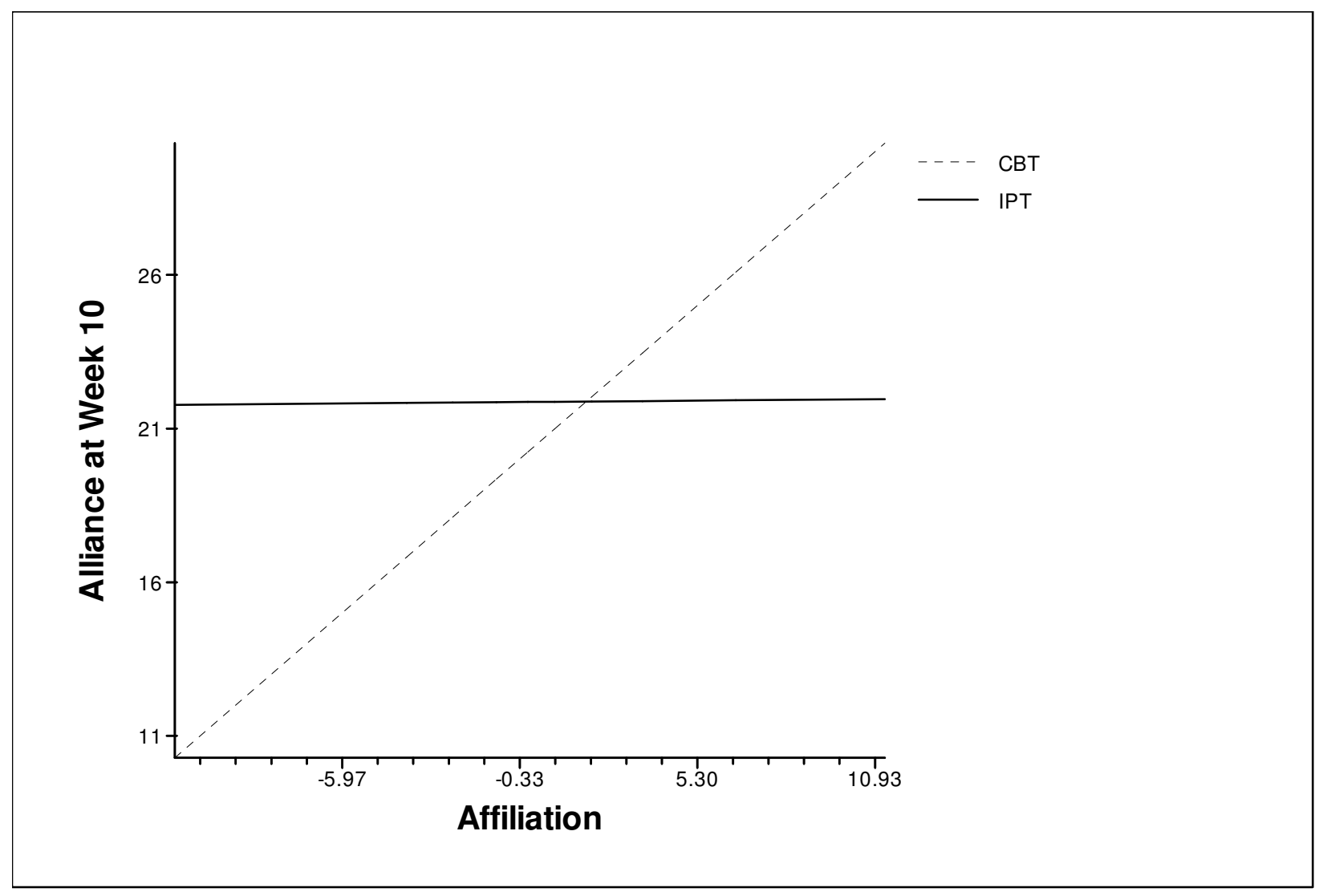


Figure 6. Rates of growth in the alliance in two treatment groups.

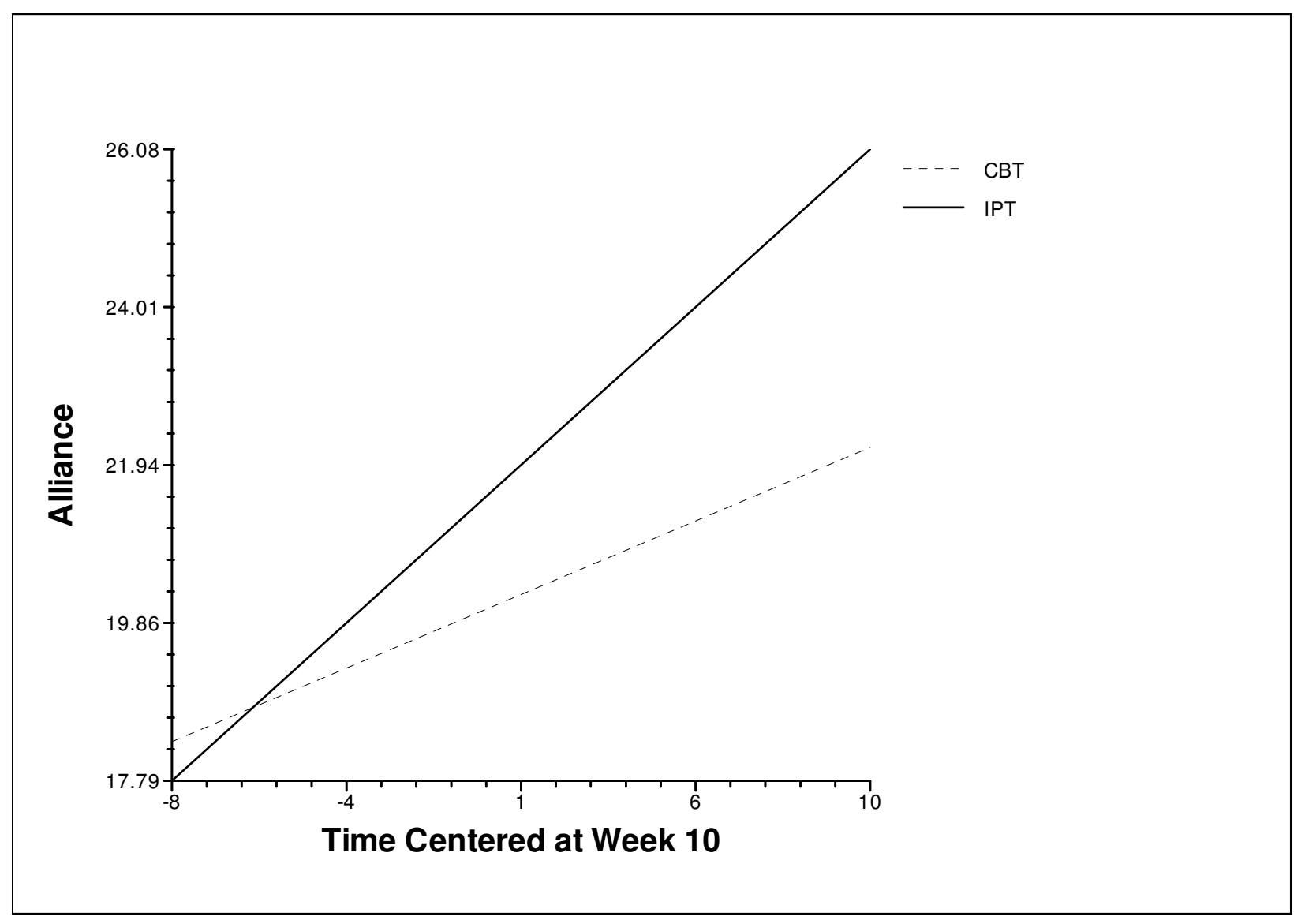


Figure 7. Three alliance trajectory groups.

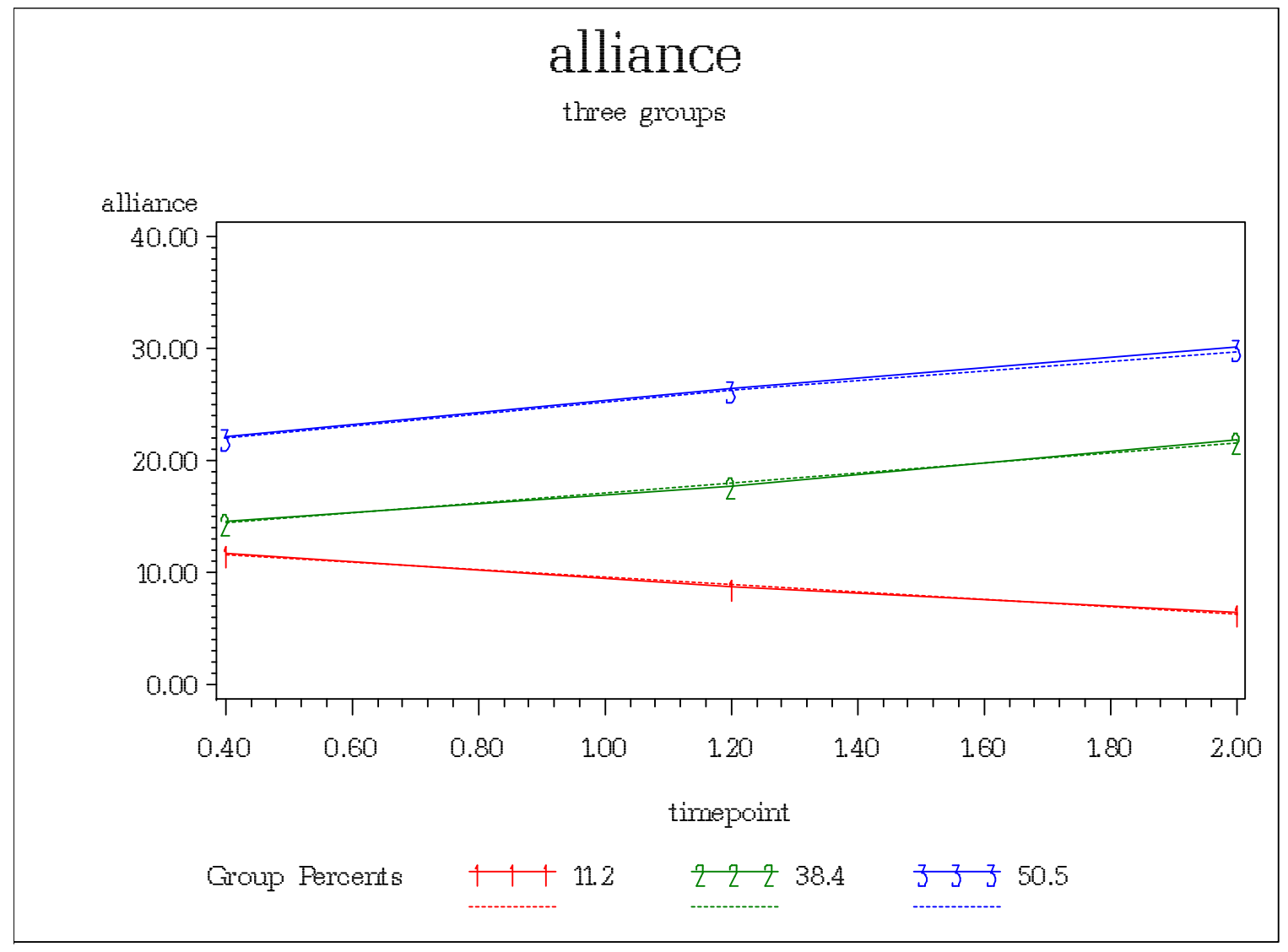


Figure 8. Multivariate outlier from Level 2 residuals in the HLM analysis predicting middle alliance.

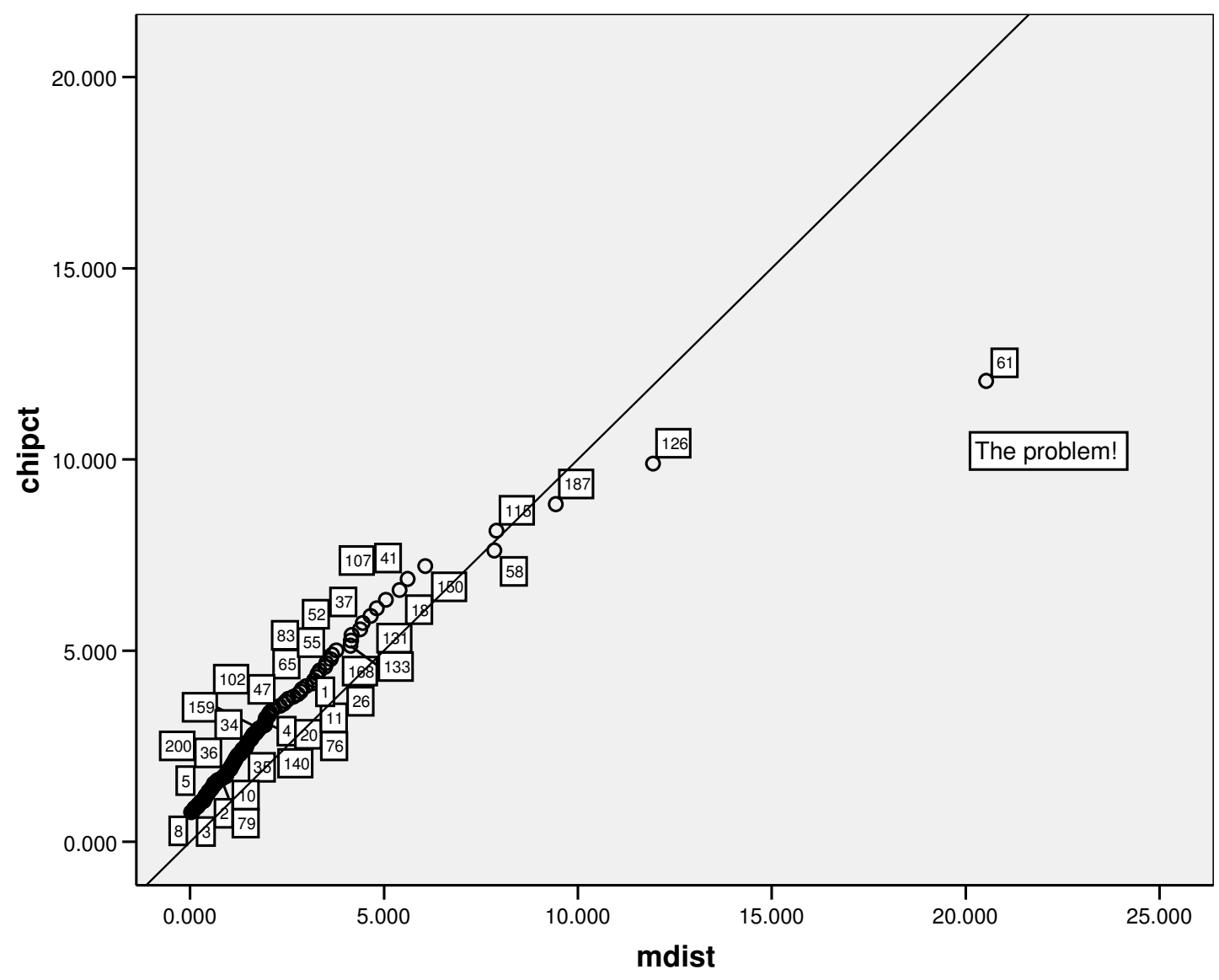




\section{BIBLIOGRAPHY}

Ackerman, S. J., \& Hilsenroth, M. J. (2001). A review of therapist characteristics and techniques negatively impacting the therapeutic alliance. Psychotherapy: Theory, Research, Practice, Training, 38, 171-185.

Ackerman, S. J., \& Hilsenroth, M. J. (2003). A review of therapist characteristics and techniques positively impacting the therapeutic alliance. Clinical Psychology Review, 23, 1-33.

Afifi, A., Clark, V. A., \& May, S. (2004). Computer-aided multivariate analysis. Boca Raton: Chapman \& Hall.

Agras, W. S. (1993). Short-term psychological treatments for binge eating. In C. G. Fairburn, \& G. T. Wilson (Eds.), Binge eating: Nature, assessment, and treatment (pp. 270-286). New York: Guilford Press.

Agras, W. S., Walsh, T., Fairburn, C. G., Wilson, G. T., \& Kraemer, H. C. (2000). A multicenter comparison of cognitive-behavioral therapy and interpersonal psychotherapy for bulimia nervosa. Archives of General Psychiatry, 57, 459-466.

Alden, L. E., Wiggins, J. S., \& Pincus, A. L. (1990). Construction of circumplex scales for the inventory of interpersonal problems. Journal of Personality Assessment, $55,521-536$.

Alexander, L. B., \& Luborsky, L. (1986). The penn helping alliance scales. In L. S. Greenberg, \& W. M. Pinsof (Eds.), The psychotherapeutic process: A research handbook (pp. 325-366). New York: The Guilford Press.

American Psychiatric Association. (1987). Diagnostic and statistical manual of mental disorders (3rd ed., rev.). Washington, DC: Author. 
Bachelor, A., \& Salamé, R. (2000). Participants' perceptions of dimensions of the therapeutic alliance over the course of therapy. Journal of Psychotherapy Practice \& Research, 9, 39-53.

Bartholomew, K., \& Horowitz, L. M. (1991). Attachment styles among young adults: A test of a four-category model. Journal of Personality and Social Psychology, 61, 226-244.

Beck, A. T., \& Steer, R. A. (1990). Beck Anxiety Inventory: Manual. San Antonio, TX: The Psychological Corporation.

Beck, A. T., Steer, R. A., \& Brown, G. K. (1996). Beck Depression Inventory - Second Edition: Manual. San Antonio, TX: The Psychological Corporation.

Beretta, V., de Roten, Y., Drapeau, M., Kramer, U., Favre, N., \& Despland, J. (2005). Clinical significance and patients' perceived change in four sessions of brief psychodynamic intervention: Characteristics of early responders. Psychology and Psychotherapy: Theory, Research and Practice, 78, 347-362.

Bordin, E. S. (1979). The generalizability of the psychoanalytic concept of the working alliance. Psychotherapy: Theory, Research \& Practice, 16, 252-260.

Bordin, E. S. (1994). Theory and research on the therapeutic working alliance: New directions. In A. O. Horvath, \& L. S. Greenberg (Eds.), The working alliance: Theory, research, and practice (pp. 13-37). Oxford, England: John Wiley \& Sons. Carson, R. C. (1969). Interaction concepts of personality. Oxford, England: Aldine Publishing Co. 
Castonguay, L. G., \& Beutler, L. E. (2006). Principles of therapeutic change: A task force on participants, relationships, and techniques factors. Journal of Clinical Psychology, 62, 631-638.

Castonguay, L. G., Constantino, M. J., \& Grosse Holtforth, M. (2006). The working alliance: Where are we and where should we go? Psychotherapy: Theory, Research, Practice, Training, 43, 271-279.

Cohen, J. (1988). Statistical power analysis for the behavioral sciences $\left(2^{\text {nd }}\right.$ ed.). Mahwah, NJ: Erlbaum.

Connolly Gibbons, M. B., Crits-Christoph, P., de la Cruz, C., Barber, J. P., Siqueland, L., \& Gladis, M. (2003). Pretreatment expectations, interpersonal functioning, and symptoms in the prediction of the therapeutic alliance across supportiveexpressive psychotherapy and cognitive therapy. Psychotherapy Research, 13, 5976.

Constantino, M. J., Arnow, B. A., Blasey, C., \& Agras, W. S. (2005). The association between patient characteristics and the therapeutic alliance in cognitivebehavioral and interpersonal therapy for bulimia nervosa. Journal of Consulting and Clinical Psychology, 73, 203-211.

Constantino, M. J., Castonguay, L. G., \& Schutt, A. J. (2002). The working alliance: A flagship for the scientist-practitioner model in psychotherapy. In G.S. Tryon (Ed.), Counseling based on process research: Applying what we know (pp. 81131). Boston: Allyn \& Bacon. 
Cooper, Z., \& Fairburn, C. (1987). The eating disorder examination: A semi-structured interview for the assessment of the specific psychopathology of eating disorders. International Journal of Eating Disorders, 6, 1-8.

Derogatis, L. R. (1977). SCL-90: Administration, Scoring and Procedures Manual-I for the Revised Version. Baltimore, MD: The Johns Hopkins Hospital.

Derogatis, L. R. (1993). Brief Symptom Inventory: Administration, Scoring, and Procedures Manual. Minneapolis, MN: National Computer Systems.

Dolan, R. T., Arnkoff, D. B., \& Glass, C. R. (1993). Client attachment style and the psychotherapist's interpersonal stance. Psychotherapy: Theory, Research, Practice, Training, 30, 408-412.

D’Unger, A., Land, K., McCall, P., \& Nagin, D. (1998). How many latent classes of delinquent/criminal careers? Results from mixed Poisson regression analyses of the London, Philadelphia, and Racine cohort studies. American Journal of Sociology, 103, 1593-1630.

Eames, V., \& Roth, A. (2000). Patient attachment orientation and the early working alliance: A study of patient and therapist reports of alliance quality and ruptures. Psychotherapy Research, 10, 421-434.

Fairburn, C. G. (1997). Interpersonal psychotherapy for bulimia nervosa. In D. M. Garner, \& P. E. Garfinkel (Eds.), Handbook of treatment for eating disorders (2nd ed.) (pp. 278-294.) New York: The Guilford Press.

Fairburn, C. G. and Cooper, Z. (1993). The Eating Disorder Examination. In C. G Fairburn and G. T. Wilson (Eds.), Binge eating: Nature, assessment, and treatment (pp. 317-360). New York: The Guildford Press. 
Fairburn, C. G., Jones, R., Peveler, R. C., \& Hope, R. A. (1993). Psychotherapy and bulimia nervosa: Longer-term effects of interpersonal psychotherapy, behavior therapy, and cognitive behavior therapy. Archives of General Psychiatry, 50, 419428.

Fairburn, C. G., Marcus, M. D., \& Wilson, G. T. (1993). Cognitive-behavioral therapy for binge eating and bulimia nervosa: A comprehensive treatment manual. In C. G. Fairburn, \& G. T. Wilson (Eds.), Binge eating: Nature, assessment, and treatment (pp. 361-404). New York: The Guilford Press.

Gaston, L., Marmar, C. R., Thompson, L. W., \& Gallagher, D. (1988). Relation of patient pretreatment characteristics to the therapeutic alliance in diverse psychotherapies. Journal of Consulting and Clinical Psychology, 56, 483-489.

Gurtman, M. B. (1992). Construct validity of interpersonal personality measures: The interpersonal circumplex as a nomological net. Journal of Personality and Social Psychology, 63, 105-118.

Gurtman, M. B. (1996). Interpersonal problems and the psychotherapy context: The construct validity of the inventory of interpersonal problems. Psychological Assessment, 8, 241-255.

Gurtman, M. B., \& Balakrishnan, J. D. (1998). Circular measurement redux: The analysis and interpretation of interpersonal circle profiles. Clinical Psychology: Science and Practice, 5, 344-360.

Gurtman, M. B., \& Pincus, A. L. (2003). The circumplex model: Methods and research applications. In J. A. Schinka, \& W. F. Velicer (Eds.), Handbook of psychology: Research methods in psychology, Vol. 2. (pp. 407-428). John Wiley \& Sons, Inc. 
Henry, W. P., Schacht, T. E., Strupp, H. H., \& Butler, S. F. (1993). Effects of training in time-limited dynamic psychotherapy: Mediators of therapists' responses to training. Journal of Consulting and Clinical Psychology, 61, 441-447.

Henry, W. P., \& Strupp, H. H. (1994). The therapeutic alliance as interpersonal process. In A. O. Horvath, \& L. S. Greenberg (Eds.), The working alliance: Theory, research, and practice (pp. 51-84). Oxford, England: John Wiley \& Sons.

Hersoug, A. G. (2004). Assessment of therapists' and patients' personality: Relationship to therapeutic technique and outcome in brief dynamic psychotherapy. Journal of Personality Assessment, 83, 191-200.

Hersoug, A. G., Hoglend, P., Monsen, J. T., \& Havik, O. E. (2001). Quality of working alliance in psychotherapy: Therapist variables and patient/therapist similarity as predictors. Journal of Psychotherapy Practice \& Research, 10, 205-216.

Hilliard, R. B., Henry, W. P., \& Strupp, H. H. (2000). An interpersonal model of psychotherapy: Linking patient and therapist developmental history, therapeutic process, and types of outcome. Journal of Consulting and Clinical Psychology, $68,125-133$.

Horowitz, L. M. (2004). Interpersonal foundations of psychopathology. Washington, DC: American Psychological Association.

Horowitz, L. M., Alden, L. E., Wiggins, J. S., \& Pincus, A. L. (2000). Inventory of Interpersonal Problems: Manual. The Psychological Corporation, a Harcourt Assessment Company. 
Horowitz, L. M., Rosenberg, S. E., Baer, B. A., Ureno, G., \& Villasenor, V. S. (1988). Inventory of Interpersonal Problems: Psychometric properties and clinical applications. Journal of Consulting and Clinical Psychology, 56, 885-892.

Horvath, A. O., \& Bedi, R. P. (2002). The alliance. In J. C. Norcross (Ed.), Psychotherapy relationships that work: Therapist contributions and responsiveness to patients (pp. 37-69). New York, NY: Oxford University Press.

Horvath, A. O., \& Marx, R. W. (1991). The development and decay of the working alliance during time-limited counseling. Canadian Journal of Counseling, 24, 240-259.

Horvath, A. O., \& Symonds, B. D. (1991). Relation between working alliance and outcome in psychotherapy: A meta-analysis. Journal of Counseling Psychology, $38,139-149$.

Kiesler, D. J. (1983). The 1982 interpersonal circle: A taxonomy for complementarity in human transactions. Psychological Review, 90, 185-214.

Kiesler, D. J. (1986). The 1982 interpersonal circle: An analysis of DSM-III personality disorders. In T. Millon, \& G. L. Klerman (Eds.), Contemporary directions in psychopathology: Toward the DSM-IV (pp. 571-597). New York: The Guilford Press.

Kiesler, D. J. (1996). Contemporary interpersonal theory and research: Personality, psychopathology, and psychotherapy. Oxford, England: John Wiley \& Sons.

Kiesler, D. J., \& Watkins, L. M. (1989). Interpersonal complementarity and the therapeutic alliance: A study of relationship in psychotherapy. Psychotherapy: Theory, Research, Practice, Training, 26, 183-194. 
Kivlighan, D. M. J., \& Shaughnessy, P. (2000). Patterns of working alliance development: A typology of client's working alliance ratings. Journal of Counseling Psychology, 47, 362-371.

Klerman, G. L., Weismann, M. M., Rounsaville, B. J., \& Chevron, E. S. (1984). Interpersonal psychotherapy for depression. New York: Basic Books.

Kokotovic, A. M., \& Tracey, T. J. (1990). Working alliance in the early phase of counseling. Journal of Counseling Psychology, 37, 16-21.

Krupnick, J. L., Sotsky, S. M., Simmens, S., \& Moyer, J. (1996). The role of the therapeutic alliance in psychotherapy and pharmacotherapy outcome: Findings in the National Institute of Mental Health treatment of depression collaborative research program. Journal of Consulting and Clinical Psychology, 64, 532-539.

Leary, T. (1957). Interpersonal diagnosis of personality: a functional theory and methodology for personality evaluation. Oxford, England: Ronald Press.

Loeb, K. L., Wilson, G. T., Labouvie, E., Pratt, E. M., Hayaki, J., \& Walsh, B. T. et al. (2005). Therapeutic alliance and treatment adherence in two interventions for bulimia nervosa: A study of process and outcome. Journal of Consulting and Clinical Psychology, 73, 1097-1107.

Luborsky, L. (1976). Helping alliances in psychotherapy. In J. L. Cleghhorn (Ed.), Succesful Psychotherapy (pp. 92-116). New York: Bruner/Mazel.

Luborsky, L., Barber, J. P., Siqueland, L., \& Johnson, S. (1996). The revised helping alliance questionnaire (HAq-II): Psychometric properties. Journal of Psychotherapy Practice \& Research, 5, 260-271. 
Markowitz, J. C., Friedman, R. A., Miller, N., Spielman, L. A., Moran, A., \& Kocsis, L. (1996). Interpersonal improvement in chronically depressed patients treated with desipramine. Journal of Affective Disorders, 41, 59-62.

Martin, D. J., Garske, J. P., \& Davis, M. K. (2000). Relation of the therapeutic alliance with outcome and other variables: A meta-analytic review. Journal of Consulting and Clinical Psychology, 68, 438-450.

Muran, J. C., Segal, Z. V., Samstag, L. W., \& Crawford, C. E. (1994). Patient pretreatment interpersonal problems and therapeutic alliance in short-term cognitive therapy. Journal of Consulting and Clinical Psychology, 62, 185-190.

Nevo, R. (2002). Interpersonal problems as they affect the development of therapeutic alliance and group climate in group psychotherapy for women survivors of childhood sexual abuse (Doctoral dissertation, Pacific Graduate School of Psychology, 2002). Dissertation Abstracts International, 63, 3-B.

Norcross, J. C. (2002). Empirically supported therapy relationships. In J. C. Norcross (Ed.), Psychotherapy relationships that work: Therapist contributions and responsiveness to patients (pp. 3-16). New York: Oxford University Press.

Paivio, S. C., \& Bahr, L. M. (1998). Interpersonal problems, working alliance, and outcome in short-term experiential therapy. Psychotherapy Research, 8, 392-407.

Patton, M. J., Kivlighan, D. M. J., \& Multon, K. D. (1997). The Missouri psychoanalytic counseling research project: Relation of changes in counseling process to client outcomes. Journal of Counseling Psychology, 44, 189-208. 
Pincus, A. L., \& Ansell, E. B. (2003). Interpersonal theory of personality. In T. Millon, \& M. J. Lerner (Eds.), Handbook of psychology: Personality and social psychology, vol. 5 (pp. 209-229). Hoboken, NJ: John Wiley \& Sons, Inc.

Piper, W. E., Azim, H. F., Joyce, A. S., \& McCallum, M. (1991). Quality of object relations versus interpersonal functioning as predictors of therapeutic alliance and psychotherapy outcome. Journal of Nervous and Mental Disease, 179, 432-438.

Piper, W. E., Boroto, D. R., Joyce, A. S., \& McCallum, M. (1995). Pattern of alliance and outcome in short-term individual psychotherapy. Psychotherapy: Theory, Research, Practice, Training, 32, 639-647.

Rogers, C. R. (1957). The necessary and sufficient conditions of therapeutic personality change. Journal of Consulting Psychology, 21, 95-103.

Rubino, G., Barker, C., Roth, T., \& Fearon, P. (2000). Therapist empathy and depth of interpretation in response to potential alliance ruptures: The role of therapist and patient attachment styles. Psychotherapy Research, 10, 408-420.

Ruiz, M. A., Pincus, A. L., Borkovec, T. D., Echemendia, R. J., Castonguay, L. G., \& Ragusea, S. A. (2004). Validity of the inventory of interpersonal problems for predicting treatment outcome: An investigation with the Pennsylvania practice research network. Journal of Personality Assessment, 83, 213-222.

Safran, J. D., \& Muran, J. C. (1996). The resolution of ruptures in the therapeutic alliance. Journal of Consulting and Clinical Psychology, 64, 447-458.

Safran, J. D., \& Muran, J. C. (2000a). Negotiating the therapeutic alliance: A relational treatment guide. New York: The Guilford Press. 
Safran, J. D., \& Muran, J. C. (2000b). Resolving therapeutic alliance ruptures: Diversity and integration. Journal of Clinical Psychology, 56, 233-243.

Safran, J. D., Muran, J. C., Samstag, L. W., \& Stevens, C. (2001). Repairing alliance ruptures. Psychotherapy, 38, 406-412.

Safran, J. D., \& Segal, Z. V. (1990). Interpersonal process in cognitive therapy. Lanham, MD: Jason Aronson, Inc.

Saunders, S. M. (2001). Pretreatment correlates of the therapeutic bond. Journal of Clinical Psychology, 57, 1339-1352.

Spitzer, R. L., Williams, J. B., Gibbson, M., \& First, M. B. (1989). Structured Clinical Interview for the DSM-III-R. Washington, DC: American Psychiatric Association.

Stiles, W. B., Glick, M. J., Osatuke, K., Hardy, G. E., Shapiro, D. A., \& Agnew-Davies, R., et al. (2004). Patterns of alliance development and the rupture-repair hypothesis: Are productive relationships U-shaped or V-shaped? Journal of Counseling Psychology, 51, 81-92.

Vittengl, J. R., Clark, L. A., \& Jarrett, R. B. (2003). Interpersonal problems, personality pathology, and social adjustment after cognitive therapy for depression. Psychological Assessment, 15, 29-40.

Wampold, B. E. (2001). The great psychotherapy debate: Models, methods, and findings. Mahwah, NJ: Lawrence Erlbaum Associates.

Ward, J. H. (1963). Hierarchical grouping to optimize objective function. Journal of the American Statistical Association, 58, 236-244. 
Wiggins, J. S. (1982). Circumplex models of interpersonal behavior in clinical psychology. In P.C. Kendall, \& J. N. Butcher (Eds.), Handbook of research methods in clinical psychology (pp. 183-221). New York: Wiley. 